\title{
LAS REPRESENTACIONES DE QUETZALCÓATL EN EL ARTE CONTEMPORÁNEO MEXICANO
}

LOUISE NOELLE

La figura de Quetzalcóatl, deidad y personaje mítico, ha sido objeto de numerosos y controvertidos estudios. Esto se debe al atractivo que este "hombre-dios" ha ejercido sobre los historiadores a través del tiempo, quienes, al enfrentarse a fuentes y documentos contradictorios, han creado buen número de confusiones. ${ }^{1} \mathrm{El}$ objeto de este trabajo no es dilucidar este dilema, ni aportar noticias sobre el origen del personaje, sino que busca analizar las diversas representaciones que de Quetzalcóatl han hecho los artistas plásticos mexicanos en el siglo XX. Es claro que estos últimos se han basado en la iconografía prehispánica, que es variada, como en los conceptos enunciados por estudiosos que enfocan el tema bajo distintas perspectivas; el resultado, de gran riqueza, ilustra las contradicciones que presentan los textos, a la vez que muestra el concepto personal de cada creador.

El primer enigma lo conforma la dualidad de Quetzalcóatl mismo, cuyo nombre refiere a la vez a una deidad y a un sacerdote-gobernante; además, este mismo personaje recibe diversos nombres siguiendo las zonas culturales o sus variadas personificaciones, tal y como Ce-Acatl Topiltzin, Nacxitl, Tepeuhqui, Meconetzin, Ahpop, Guatezuma, Ehécatl, Kukulcán, Tlahuizcalpantecutli, Tohil, y algunos más, con lo que la confusión aumenta. Es preciso, por lo tanto, revisar sumariamente las principales teorías sobre este tema para lograr comprender posteriormente las expresiones actuales. ${ }^{2}$

Serpiente con plumas de quetzal es el significado de la palabra Quetzalcóatl, que designa a un dios prehispánico que tiene advocaciones de Ehécatl, y Tlahuizcalpantecutli, cuyas acciones tienen un signo benéfico.

1 Numerosos son los textos sobre Quetzalcóatl desde la época de la Colonia; Alfredo López Austin en Hombre-dios. Religión y política del mundo náhuatl, UNAM, México, 1973, hace una revisión crítica de los mismos con base en las fuentes históricas, mostrando las principales corrientes interpretativas. Asimismo, este historiador acuñó el término "hombre-dios".

2 Esta revisión se basa primordialmente en los libros de Miguel León Portilla, Quetzalcóatl, F.C.E., México, 1968, y Román Piña Chan, Quetzalcóatl, serpiente emplumada, F.C.E., México, 1977. 
Su importancia en el panteón prehispánico es indiscutible, pues se le considera como una de las cuatro deidades principales creadas por Ometecuhtli y Omecíhuatl, señores del universo, a la que le corresponde uno de los cuatro cuadrantes del mundo, aunque la información varía según las fuentes. Asimismo la representación de la serpiente emplumada y el gran número de símbolos que se le adjudican, se inicia desde el periodo preclásico mesoamericano en casos aislados, como en La Venta, ${ }^{3}$ y que adquiere mayor importancia, al parecer, a partir del período clásico nahua, en sitios como Teotihuacan, Yaxchilan o Xochicalco, tanto en el marco de los conjuntos arquitectónicss, esculturas, relieves y pinturas murales, como en objetos que van desde la cerámica y diversos adornos, hasta los códices. Baste recordar la pirámide de Tláloc-Quetzalcóatl, en Teotihuacan, con los relieves del cuerpo de la serpiente emplumada terminados en imponentes esculturas de la cabeza del ofidio, o el basamento del edificio principal de Xochicalco, donde una serpiente emplumada en relieve conforma el motivo principal de las decoraciones del talud.

Sin embargo, la deidad Quetzalcóatl tuvo otras iconografías, fuera de la de la serpiente emplumada y que corresponden a su identificación con advocaciones de Ehécatl y Tlahuizcalpantecutli, que varían dependiendo de los atributos y su simbología, así como con las imágenes de los sam cerdotes que tienen a su cargo el culto de esas deidades. La primera variante podría ser la de la propia serpiente emplumada que conlleva la imagen de un hombre casi siempre en sus fauces, que se puede ejemplificar en las tres estelas de Xochicalco y en algunas esculturas mexicas. ${ }^{4}$ Asimismo las representaciones de Ehécatl, hombre pájaro ligado con el viento o las de Tlahuizcalpantecutli y Xólotl, estrellas matutina y vespertina, se confunden con las propias de Quetzalcóatl; así, en el Códice Borgia y en el Códice Viena, Quetzalcóatl-Ehécatl es un solo personaje. ${ }^{5}$ Finalmente, es preciso anotar a los sacerdotes teotihuacanos representados en los muros de los Palacios de Tepantitla y Atetelco que sirven a Quetzalcóatil.

El segundo aspecto de este enigma se refiere a la condición humana

3 Lápida de La Venta, Tab., Monumento 19, con una representación de una serpiente de cascabel alada, símbolo de la lluvia.

4 Se trata de serpientes con una cabeza humana que sale de sus fauces; entre otras, se localizan dos en el Museo del Hombre, en París, y una más en el Museo Nacional de Antropología, México. Cf. Nelly Gutiérrez Solana, Las serpientes en el arte mexica, UNAM, México, 1987.

5 Cf. láminas 19 y 56 del Códice Borgia y 48 del Códice Viena. 
de un sacerdote-gobernante que lleva el mismo nombre de Quetzalcóatl; se puede decir que es esta vertiente la que más ha fascinado a propios y extraños, favoreciendo con ello numerosas interpretaciones y dando lugar al surgimiento de un mito. Se trata probablemente de un hombre denominado Ce-Acatl Topiltzin, puesto que había nacido el día 1 caña, del año 1 caña $(\mathrm{Ce}=$ uno, $\mathrm{Acatl}=$ caña $)$, según algunos del vientre de una virgen, Chimalma, aunque en otros casos se registra que su padre fue Mixcóatl. Después de algunos hechos heroicos, como el vencer a Tepotztécatl, asesino de su padre, llegó a Tula convirtiéndose en su gobernante; allí, como sacerdote de Quetzalcóatl, introdujo su culto, preocupándose por iniciar a los toltecas no sólo en una religión luminosa y benéfica, fundada en un comportamiento moral que proscribía los sacrificios humanos, sino también en la búsqueda del conocimiento y el cultivo de las artes. Las fuerzas malignas de los seguidores de Tezcatlipoca lo hicieron romper su voto de castidad, por lo que salió huyendo de Tula hacia la costa del Golfo de México. De su fin se tienen dos versiones: la primera relata un autosacrificio en una hoguera de la que salió convertido en Tlahuizcalpantecutli-Xólotl, ${ }^{6}$ y la segunda narra cómo al llegar al mar, en una balsa de serpientes, se dirigió al Tlillan-Tlalpallan, tierra del saber, para reaparecer en Yucatán, donde fue conocido con el nombre de Kukulcán. También es importante anotar que es muy probable que los gobernantes-sacerdotes nahuas que llevaban ocasionalmente el nombre de su dios, Quetzalcóatl, fuesen confundidos con éste, por lo que sus hechos heroicos y benéficos enriquecen y confunden aún más la leyenda. De estas narraciones del héroe deidificado, Ce-Acatl Topiltzin Quetzalcóatl, existen, tanto en las fuentes como en las interpretaciones posteriores, numerosas variantes. Por ello diversos historiadores to han identificado con un personaje europeo, portador de la religión católica, que en el caso de los textos de fray Bartolomé de las Casas o de Carlos de Sigüenza y Góngora toma la figura de Santo Tomás.? Tal vez la descripción física del personaje como la de un hombre blanco y barbado, atributos de Tláloc, favoreciera que el propio Moctezuma lo hubiese confundido con Hernán Cortés, y los españoles del virreinato con algún evangelizador.

De este modo la iconografía antigua sobre el hombre-dios es diversa, y básicamente está dividida en dos vertientes. La primera, esencialmente

6 Cf. lámina 30 del Códice Borgia. Esta estrella es el planeta Venus.

$\checkmark$ Alfredo López Austin, Hombre-dios. Religión y politica en el mundo náhuatl, UNAM, México, 1973, pp. 16 y 21. 
maya, se refiere a la presencia de Kukulcán en tierras yucatecas, ya sea bajo la forma de un rostro que emerge de fauces ofidianas, o de los sacerdotes que cuidan del culto de ese dios serpentino. ${ }^{8}$ En el segundo caso, los principales ejemplos se encuentran en los códices, que narran la vida de Ce-Acatl Topiltzin, y que conservan el enfoque de su historia como la de un ser humano heroico. ${ }^{9}$ En todo caso, la relación de los hechos sobresalientes de la gesta de este personaje continúan como fuente de inspiración para nuestros artistas y escritores, y su figura se ha integrado a la cultura del México actual.

Se puede por lo tanto afirmar que, en el complejo cultural mesoamericano, Quetzalcóatl es equivalente de religiosidad, sabiduría y creación cósmica y cultural. ${ }^{10}$ Por ello es comprensible que su figura sea tan atractiva para todos aquellos que buscan en lo mexicano una inspiración para su quehacer artístico. En efecto, el siglo $\mathrm{XX}$ ha sido, en diversos ámbitos, propicio para el desarrollo de sentimientos nacionalistas; la preponderancia de la Academia de Beaux Arts de París a finales del siglo pasado y la dominación de ciertas corrientes vanguardistas internacionales en el campo de las artes, han provocado en buen número de creadores una postura de rechazo de lo externo en pro de una expresión propia. En México esto se vio agudizado a partir de la Revolución Mexicana, que propició en el ámbito cultural un redescubrimiento y aprecio de lo local. A los artistas que privilegiaron el legado prehispánico frente al pasado colonial, figuras como las de este hombre-dios, representante de lo más noble y elevado del espiritualismo del México precolombino, ofrece en sus diversas concepciones una rica y atractiva fuente de inspiración.

Hacia 1922 surgió en México, en el campo de las artes plásticas, una renovación con un marcado carácter nacionalista. Quienes formaron la parte inicial de este movimiento fueron los pintores muralistas que, dos años más tarde, dieron las bases para la formación de un sindicato que

8 Los ejemplos pueden ser, entre muchos otros, la escultura en piedra procedente de Uxmal, en el Museo Nacional de Antropología, conocida como "Reina de Uxmal", que representa a una cabeza de serpiente con un rostro humano entre sus fauces, y el relieve de los sacerdotes en el templo de Kukulkán, Chichén Itzá, donde los dirigentes del culto aparecen con el rostro dentro de las fauces de una serpiente, acompañados de diversos atributos del dios.

$9 \mathrm{El}$ Códice Florentino es el más rico en estos ejemplos, aunque también se encuentran en el Códice Matritense del Real Palacio," posteriormente, el Atlas de fray Diego de Durán, también mostrará a este héroe como un sabio sacerđote barbado sobre un estrado adornado con serpientes.

10 León Portilla, op. cit., p. 7. 
reuniera a todos los artistas identificados con el movimiento social que propició la Revolución iniciada en 1910; la denominación que acordaron darle fue: Sindicato de pintores, escultores y grabadores de México. En el manifiesto o Declaración social, politica y estética que publicaron, entre otras cosas asentaron que "hasta la mínima expresión de la vida espiritual y física de nuestra raza, brota de lo nativo (y particularmente 10 indio) ". ${ }^{11}$ En realidad, con tal declaración continuaban con la valorización que del arte prehispánico iniciara Manuel G. Revilla a finales del siglo XIX, retomada más tarde por Manuel Gamio; ${ }^{12}$ consideradas las cosas así, los pintores post-revolucionarios volvieron los ojos hacia el pasado indigena. Del estudio de las culturas mesoamericanas, fueron diversos los resultados, dada la riqueza de la fuente de inspiración; sin embargo, cabe apuntar que Quetzalcóatl y su mito tuvieron especial interés, por el enigma del personaje; su dualidad humana y divina, y la abundancia de símbolos hicieron de este parangón de la cultura y la virtud antiguas un tema recurrente en la plástica contemporánea mexicana.

Quien primero plasmó en los muros la imagen de Quetzalcóatl fue Diego Rivera, pionero en muchos sentidos; lo hizo en 1929 en el muro norte de la escalera monumental del Palacio Nacional. En la obra "Historia de México desde la época prehispánica al futuro", Rivera se ocupó del pasado precolombino. La composición está dividida en dos escenas, una inferior sobre la guerra, y la superior referida a la cultura, en cuyo centro se localiza Quetzalcóatl, el sacerdote-gobernante; se trata de un hombre blanco y barbado, como reza la leyenda, rodeado de otros sacerdotes a quienes transmite su saber, que a su vez se difunde por el mundo prehispánico. Este personaje, para mayor identificación, porta sobre su cabeza un penacho de plumas de quetzal, sobre su pecho un caracol, símbolo de su relación con el agua y el viento, y en la mano un báculo en forma de voluta. Tanto el báculo como el caracol están tomados del Códice Florentino, ${ }^{13}$ mismo que le sirviera de inspiración para la representación del hombre-dios que en la parte superior del mural se aleja sobre una serpiente voladora. La relación entre Quezalcóatl y la cultura es evidente en la pintura, y la figura central, probablemente

11 Ida Rodríguez Prampolini, El arte contemporáneo, Pormaca, México, 1964, p. 105.

12 El libro de Manuel G. Revilla, El arte en México, fue publicado por primera vez en 1892, mientras que Forjando patria, de Manuel Gamio, vio la luz en 1916.

13 Cf. Códice Florentino, Libro I, lámina II. 
inspirada en el Atlas de fray Diego de Durán, ${ }^{14}$ tiene toda la dignidad de un maestro pacífico y civilizador. Finalmente, es preciso apuntar una curiosa serpiente emplumada, que semeja más bien un objeto artesanal, surgiendo de un volcán en erupción en la parte superior derecha. Si algún simbolismo tiene, es el del holocausto de Quetzalcóatl, que al morir se transforma en Xólotl, estrella vespertina, puesto que el sol está ca. yendo.

Diez años más tarde Rivera repetirá estas imágenes en el mural "Unidad Panamericana", situado en el vestíbulo del San Francisco City College. Así, en el primer panel que corresponde a la cultura prehispánica, "El genio creador del sur", está presidido por un Quetzalcóatl rodeado de sus discípulos y, al igual que en el Palacio Nacional, está representado como un homble blanco y barbado, con penacho de plumas de quetzal, pectoral de caracol y báculo en forma de voluta; en esta ocasión también se perfila como promotor y protector de las artes que se desarrollan a su alrededor. Asimismo, una serpiente emplumada, de colorido y forma similar a la que surge del volcán en el caso anterior, recorre la escena partiendo del propio templo de Quetzalcóatl; en esta ocasión remata en el segundo panel, en una enorme cabeza de ofidio en piedra, tallada por el escultor Mardonio Magaña. Es la presencia del mito no sólo en nuestro siglo, sino en tierras allende las fronteras, como un mensaje de la civilización antigua, a los pies del Golden Gate.

En el controvertido mural "Sueño de una tarde dominical en la Alameda", pintado entre 1947-1948, para el comedor del desaparecido Hotel del Prado, y localizado actualmente en un pabellón en la Plaza de la Solidaridad, Diego Rivera pintó una extraña representación de Quetzalcóatl. Aquí, el personaje central, "La calavera catrina", ${ }^{15}$ lleva alrededor del cuello un adorno a manera de una boa de plumas. Este adorno es en realidad una serpiente de cascabel emplumada, cuya forma y colorido se asemejan a las representaciones de esta deidad mesoamericana en los murales que hemos citado con anterioridad. Puesto que en este mural Rivera se ha representado como un niño que va de la mano de la calavera, podemos suponer que el artista quiso decir que el espíritu de 10 mexicano inherente en José Guadalupe Posada lo ha guiado también a él, y la inclusión de la serpiente bien puede significar la existencia de lo prehispánico en su arte.

14 Cf. Atlas de Durán, Tratado II, lámina I.

15 La cabeza de este personaje está tomada de un grabado de José Guadalupe Posada que lleva el mismo título. 
En cuatro murales más, este artista se ocupó de plasmar a Quetzalcóatl en forma de serpiente emplumada. El primer ejemplo es "El deporte", mosaico de piedra en relieve que está sobre el muro-talud del Estadio Olímpico de la Ciudad Universitaria, 1952; en esta ocasión se trata de un ofidio que corre a lo largo de la escena, como un apoyo del que surge la juventud deportiva mexicana. El caso del mural realizado al fresco en 1953 en el Hospital de la Raza es similar, puesto que la escena está sustentada sobre dos serpientes emplumadas, levemente diferentes entre sí; sendos árboles de la vida, que encuadran "El pueblo en demanda de salud", enraizan sobre los ofidios, simbolizando las raíces que el mundo actual tiene en el pasado precolombino.

De carácter más decorativo y festivo es la serpiente emplumada que flota en el límite derecho del mural "El teatro en México", realizado también en 1935, para el Teatro Insurgentes. En este mosaico Quetzalcóatl retoma su papel de deidad promotora de las artes, escénicas en esta ocasión; asimismo hay que agregar la presencia de un danzante, que con penacho emplumado y máscara de Tláloc serpentino hace referencia al mismo tema. Finalmente, dentro de esta vena decorativa se encuentra el relieve en mosaico realizado para la casa de Dolores Olmedo en Acapulco, 1956. Se trata de una enorme serpiente inspirada en los relieves de la pirámide de Tláloc-Quetzalcóatl, en Teotihuacan.

José Clemente Orozco fue el segundo artista que se ocupó del hombredios; en 1936 realizó al fresco catorce tableros mayores y diez menores en los muros de la Biblioteca Baker del Darmouth College, en los Estados Unidos de Norteamérica. Orozco tuvo una visión muy personal del mundo, misma que quedó plasmada en su obra, y el caso de Quetzalcóatl es una muestra más de su individualidad; en los paneles del mural que corresponden a la llegada y la partida del ser mitológico, lo representa como el sacerdote-gobernante, un hombre blanco y barbado de innegable filiación europea. Sin embargo, para el artista no es un personaje pacífico, sino más bien un profeta terrible que en su aspecto tiene más de un "dios padre" iracundo; esto es especialmente notorio en el panel en que aparece rodeado de feroces serpientes en un mar embravecido, en el acto de abandonar a los bárbaros indígenas. La concepción de este ser, a pesar de estar en relación con la cultura, es la de un hombre superior que condesciende a educar al mesoamericano. Dentro de esta noción es preciso anotar el magnífico dibujo a lápiz que Orozco realizara, en 1932, de la cabeza de Quetzalcóatl. Asimismo en dicho mural, en la sección que corresponde a la llegada de Quetzalcóatl, aparece la 
representación de un monolito de una cabeza ofidiana, probablemente inspirada en las muchas piezas similares del arte mesoamericano.

Entre 1938 y 1939, al pintar Orozco en el Hospicio Cabañas de Guadalajara, realizó, en la bóveda del crucero Este, el fresco "Confusión de religiones", donde aparece nuevamente Quetzalcóatl con el mismo aspecto fiero de las obras anteriormente descritas, coronado en este caso con una estrella, Tlahuizcalpantecutli o Venus. Aquí queda en claro que es una deidad más de las que conforman el sincretismo religioso de los mexicanos. En ese mismo sitio, la figura del "Hombre en llamas", estudiada en detalle por Justino Fernández, ${ }^{16}$ podría también tomarse como Quetzalcóatl en el momento de su holocausto; es la idea del hombre que purificado por el fuego resurge perfeccionado, aunque no hay ningún otro indicio que apoye esta teoría.

El pintor muralista Fermín Revueltas, en su corta obra, se ocupó del personaje mítico en uno de los seis vitrales que diseñó con el tema de "México, su historia, su riqueza y su futuro", para colocarse en el Centro Escolar Revolución en 1934. Dentro de la limitada expresividad que permite el trabajo en vidrio, podemos apreciar, en la ventana que corresponde al mundo prehispánico, la preeminencia de Quetzalcóatl, probablemente por su liga con el tema de la cultura. En la parte inferior aparece la escultura de una serpiente emplumada, y sobre ella, de entre las llamas, surge un hombre-Quetzalcóatl frente a una representación de la pirámide de Kukulkán en Chichén-Itzá. En la parte superior, se encuentra, coronándolo todo, esta deidad tomada del Códice Florentino, con su báculo ondulado y las plumas de quetzal en su tocado, así como un escudo con el símbolo del caracol.

Solamente en una ocasión se ocupó David Alfaro Siqueiros de la serpiente emplumada; lo hizo en la que fuera la casa de Angélica Arenal, localizada en las calles de Sonora número 9. Se trata de una obra en piroxilina sobre celotex y triplay realizada en 1944, actualmente reubicada en el Tecpan de Nonoalco-Tlatelolco, donde ofrece una versión temprana de lo que habria de denominar escultopintura. En la localización original del mural "Cuauhtémoc contra el mito", se encontraba al pie de la escalera la reproducción policromada de la cabeza de serpiente, copiada de la conocida pirámide de Quetzalcóatl en Teotihuacan, con la corona de plumas pintada sobre el muro. La relación entre el dios

16 Justino Fernández, Estética del arte mexicano, UNAM, México, 1972, pp. 524-55. Para Fernández es una expresión del hombre: "así es la vida humana", p. 532 . 
prehispánico como símbolo cultural y Cuauhtémoc es obvia, a pesar de que la pieza está directamente copiada del original.

Poco años después, en 1949, quien se ocupó de este tema fue el arquitecto y pintor Juan O'Gorman, en la interesante obra al temple sobre masonite "La ciudad de México", en la cual, sobre un cuidadoso paisaje urbano flota, junto al águila nacional, una serpiente emplumada. Se trata de un ofidio cuya iconografía está emparentada con la de las serpientes que pintara Diego Rivera en el Palacio Nacional; el plumaje de suave colorido y la presencia de esta leyenda sobre el México del siglo $\mathrm{XX}$, tiene resabios de la vena surrealista y fantástica de su autor.

Este prolífico artista retomará a Quetzalcóatl bajo distintas expresiones en la Biblioteca Central de Ciudad Universitaria, 1952. En el basamento de piedra-brasa del edificio, encontramos los relieves de Ehécatl, de Tláloc y de dos serpientes emplumadas. Sin embargo, en la caja del acervo bibliográfico, recubierta con los famosos murales en mosaicos de piedra, es donde encontramos representaciones más detalladas, en el muro oriental dedicado a la cultura prehispánica. En este sentido, es lógico que, en la parte central derecha del mismo, se encuentre la imagen dual de Quetzalcóatl-Mictlantecutli, inspirada en el Códice Borgia. ${ }^{17}$ Asimismo, en una franja de mosaico en la parte baja y como remate se encuentran dos pares de serpientes emplumadas, acompañadas de los símbolos que le son afines, similares a los que se encuentran en Teotihuacan. Con este sentido decorativo la representación de la serpiente emplumada se repite en diversas obras, como en los murales de mosaico de piedra, "Alegoría de México", 1954, que se localizaban en la Secretaría de Comunicaciones y Transportes, ${ }^{18}$ y "Nuestro señor Cuauhtémoc", 1956, así como en "La confluencia de las civilizaciones europeas y autóctona", realizado entre 1966 y 1967 para el Centro de Convenciones de la Hemisfair, en San Antonio, Texas. Una mención especial merecen dos serpientes localizadas en la que fuera la casa del propio O'Gorman, en la avenida San Jerónimo No. 162, México, D.F.; se distingue, por formar parte de un ensayo de arquitectura orgánica-onírica, actualmente destruido, "Dioses y símbolos del México antiguo", el tema del relieve realizado entre 1953 y 1956 con un mosaico de piedras.

José Chávez Morado es otro artista que se ha ocupado en diversas oca-

$17 \mathrm{Cf}$ Códice Borgia, lámina 56, donde Quetzalcóatl-Ehécatl está adosado a su contrario Mictlantecutli, señor de los muertos.

18 A raíz del sismo de 1985 estos murales fueron retirados, aunque se contempla su reposición parcial. 
siones de Quetzalcóatl. La primera fue en 1952 con " $E 1$ regreso de Quetzalcóatl", mural en mosaico veneciano localizado en la antigua Facultad de Ciencias de Ciudad Universitaria; aquí, sobre una balsa formada por una serpiente emplumada, llegan a América las distintas razas y culturas del mundo guiadas por Ehécatl, símbolo del pasado precolombino. El retorno del hombre-dios legendario es, en el fondo, el arribo de la cultura universal y su adaptación al mundo prehispánico.

Una concepción diferente es la que se encuentra en el mural "La magia y las ciencias médicas", 1954, realizado en mosaico en piedra en un muro exterior de los laboratorios CIBA, obra del arquitecto Alejandro Prieto. En este caso una serpiente emplumada se desarrolla a lo largo del mural rematando en la dualidad Quetzalcóatl-Mictlantecutli, inspirada en el Códice Borgia. En este caso la doble presencia de un dios benéfico y un dios del inframundo tiene una relación directa con la enfermedad y la muerte por una parte, y la medicina y la farmacéutica por la otra. En el vestíbulo, en "La medicina prehispánica" encontramos nuevamente a la serpiente emplumada, esta vez en relieve con mosaicos, mientras que frente a ella Ehécatl-Quetzalcóatl actúa como sacerdote-dios benéfico, portando tocado de plumas de quetzal y pectoral de caracol.

En "Evolución y futuro de la ciencia médica en México", 1957-1959, vasta obra de relieves en cantera que recubren los muros frontales de las aulas del Centro Médico, del arquitecto Enrique Yáñez, surge nuevamente la imagen de Quetzalcóatl. Dentro del primer panel que hace referencia al mundo prehispánico: vuela sobre la escena una serpiente emplumada con el rostro del dios entre las fauces. ${ }^{19}$ En este mismo conjunto, en la parte central se encuentra otra serpiente emplumada que rodea una escena de la medicina social; una serie de símbolos están grabados sobre el cuerpo del ofidio, cuyo significado bienhechor es evidente, puesto que el escudo nacional corona la escena.

Entre otros ejemplos debidos a José Chávez Morado, destaca el del cancel en bronce con el tema de "Componentes raciales y culturales del México moderno", 1960, localizado en el muro exterior del Museo Nacional de Historia en el Bosque de Chapultepec. En un extremo de dicho cancel se localiza una serpiente que proteje al sacerdote-dios, portador de

19 Ejemplos prehispánicos de esta iconografía pueden ser las estelas de Xochicalco o las esculturas mexicanas, mencionadas en la nota 4 , notablemente aquella que se localiza en el Museo Nacional de Antropología. 
los atributos sagrados. ${ }^{20}$ También es preciso mencionar a una deidad serpentina, que porta al sacerdote con el fuego simbólico, en el mural "Expresión cultural de Mesoamérica", 1964, en la Sala Mesoamericana del Museo Nacional de Antropología. Recientemente, en el relieve en bronce que corona el acceso al Palacio Legislativo, 1981, una serpiente de las mismas características ocupa la parte superior derecha de la composición.

Tres artistas más se ocuparon de representar a Quetzalcóatl en el año de 1952. El primero, Rodrigo Arenas Betancourt, lo hizo incluyendo una serpiente emplumada a los pies de su "Prometeo", escultura en bronce para la Facultad de Ciencias de la Ciudad Universitaria; probablemente esta inclusión alude a una apropiación mexicana del mito de Prometeo. Por su parte Alfredo Zalce, en el mural "Cuauhtémoc y la historia", introduce la cabeza de una serpiente emplumada en la parte inferior de la composición, inspirándose para ello en las cabezas de la pirámide teotihuacana de esa deidad. Finalmente, Carlos Mérida representa al dios Quetzalcóatl en el relieve de concreto policromado localizado en las escaleras exteriores de los edificios del malogrado Multifamiliar Juárez; ${ }^{21}$ con base en el tema de "El principio del mundo según la Relación de Texcoco", el artista guatemalteco representó a las cuatro deidades creadoras del mundo prehispánico tomando sus atributos de las descripciones de la Relación de Texcoco, en la que este dios se confunde con Tláloc; asimismo, hay que mencionar que las figuras de estos dioses, en actitud ceremonial de ascenso, se repitieron un buen número de veces en las cinco escaleras de los citados inmuebles.

Rufino Tamayo se ocupó en su pintura mural de representar a Quetzalcóatl, siempre como una serpiente emplumada, y con un carácter más bien decorativo. Así, en el mural "El día y la noche", localizado originalmente en el almacén "Sanborn's Reforma", al ocuparse de reproducir algunos monumentos precolombinos, incluyó una cabeza de ofidio de inspiración teotihuacana. "América", 1956, realizado para el Bank of the Southwest, Houston, Texas, presenta la misma figura, como simple referencia al pasado prehispánico. De mayor atractivo y creatividad es la serpiente que pintó conforme al mito de la encarnizada y eterna lucha que

20 Esta representación está estrechamente ligada con la del monumento 19, de La Venta, Tab.

21 A raíz del sismo de 1985, los edificios attos de la Unidad Habitacional Benito Juárez fueron dinamitados; en este caso, se trató de cinco edificios de diez pisos cuyas escaleras exentas tenían en su núcleo esta decoración. Cf. Louise Noelle, "Los murales de Carlos Mérida. Relación de un desastre", Anales del Instituto de Investigaciones Estéticas, No. 58, UNAM, México 1987, pp. 125-143. 
mantiene con el jaguar, en "Dualidad", 1964, obra situada en el vestíbulo del Museo Nacional de Antropología de la ciudad de México; se trata de una excelente muestra del arte pictórico del pintor oaxaqueño, donde el colorido y la composición simple ofrecen tensión y emoción siempre renovadas.

Por su parte Raúl Anguiano también se inspiró en este hombre-dios para algunas de sus obras. En 1956 incluyó una serpiente emplumada en el mural "La evolución del comercio en México", pintado al ćleo en el edificio de la Cámara Nacional de Comercio en la ciudad de México. Para el Museo Nacional de Antropología, 1964, pinta sendos murales: el primero, "Deidades de Mesoamérica", en la Sala Mesoamericana, muestra la representación del dios relacionado con Tláloc e identificado por su barba, báculo y pectoral, sobrepuesto a una serpiente emplumada, inspirada en los relieves de Xochicalco; contiguo está Ehécatl, portando su característica máscara de ave. Por lo que respecta al otro mural, la "Creación del hombre maya", Kukulkán, sobre una embarcación flanqueada por una serpiente, arriba a tierras yucatecas en el momento en que el pueblo maya cobra vida; este dios porta los símbolos que lo indentifican con el Quetzalcóatl de los toltecas. En ese mismo año, Anguiano realizó un mural, "Historia de los colorantes en México", para el Consorcio Químico Mexicano en Tlalnepantla, Méx., en el cual aparece la consabida figura de la serpiente mesoamericana. Hace unos años, en 1979, realizó unos óleos de gran formato sobre el tema de "La comunicación", para Publicidad Ferrer; en el que corresponde al mundo prehispánico, de un caracol dibujado por un indígena surge, a manera de una nube de humo, una serpiente emplumada que lleva entre sus fauces al hombre blanco y barbado.

Luis Nishizawa, en su único mural, titulado "El aire es vida", 1958, pintado para el vestíbulo del Hospital de Neumología, Centro Médico Nacional, ${ }^{22}$ se ocupó del dios del viento, Ehécatl, con su máscara de ave pero con un pectoral de plumas de quetzal. Este artista logró así alejarse de los modelos prehispánicos ofreciendo una figura impactante por su expresión y colorido.

Dentro de esta apretada revisión de las representaciones de Quetzalcóatl, en la que probablemente se incurre en omisiones involuntarias, es preciso incluir a algunos artistas más que se acercaron al tema en épocas

22 El Hospital de Neumología fue destruido por el sismo de 1985, y el mural, recientemente expuesto en el Palacio de Bellas Artes (noviembre-diciembre 1988), no ha sido reubicado aún. 
DOI: http://dx.doi.org/10.22201/iie.18703062e.1989.60.1532

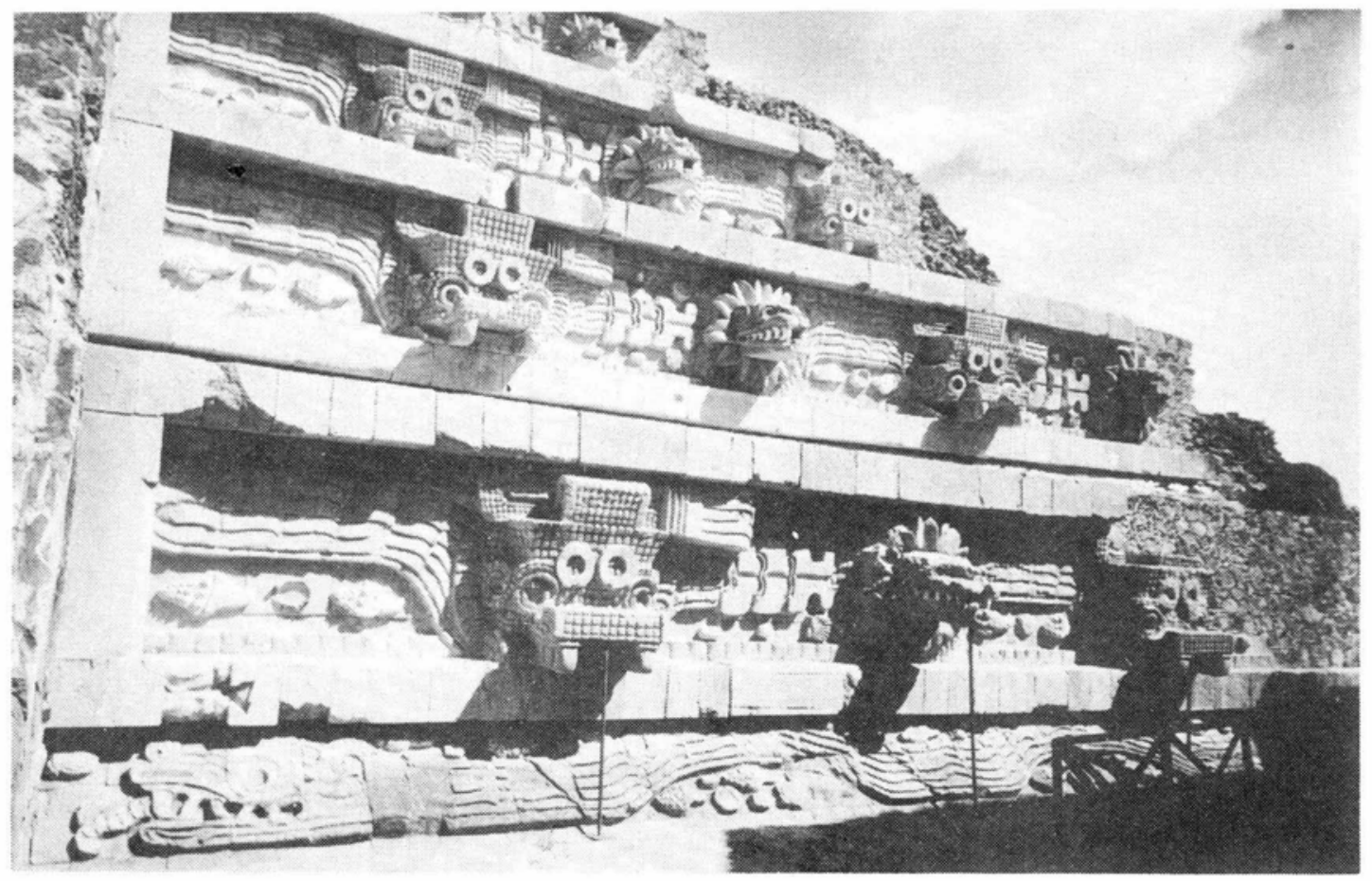

1A. Templo de Quetzalcóatl y Tláloc, Teotihuacan, Méx.

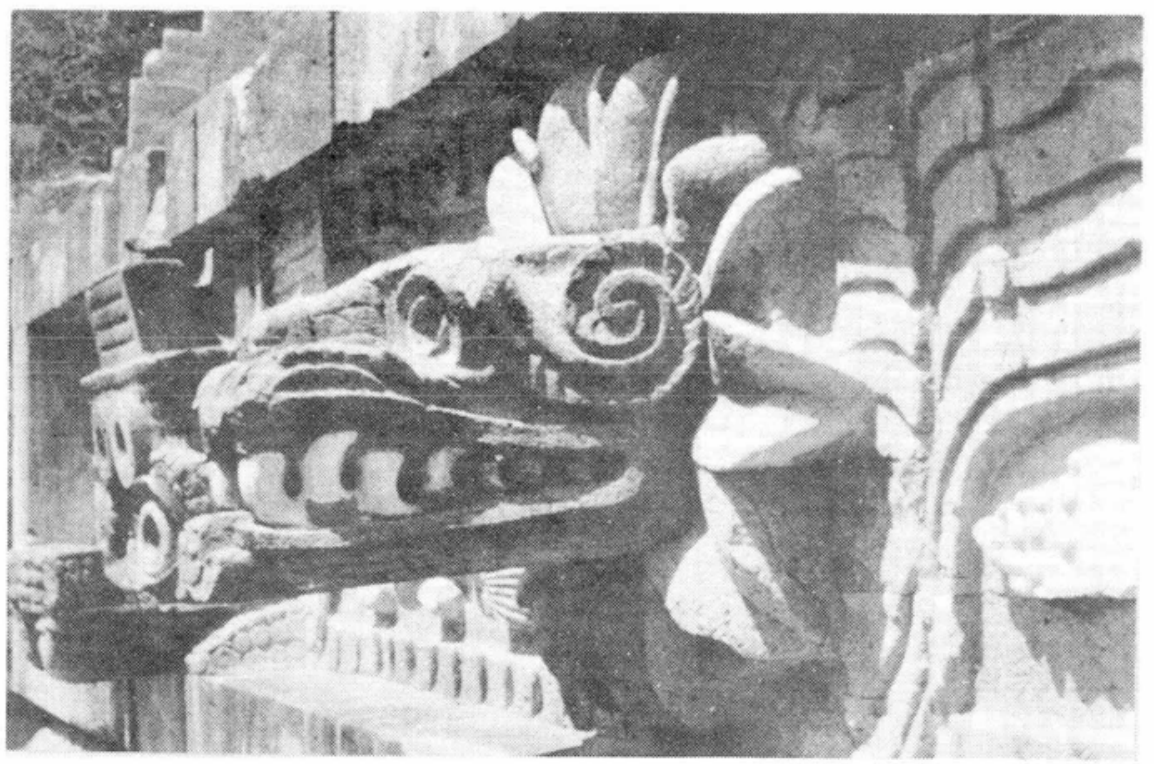

1B. Detalle de la cabeza de la serpiente emplumada. 

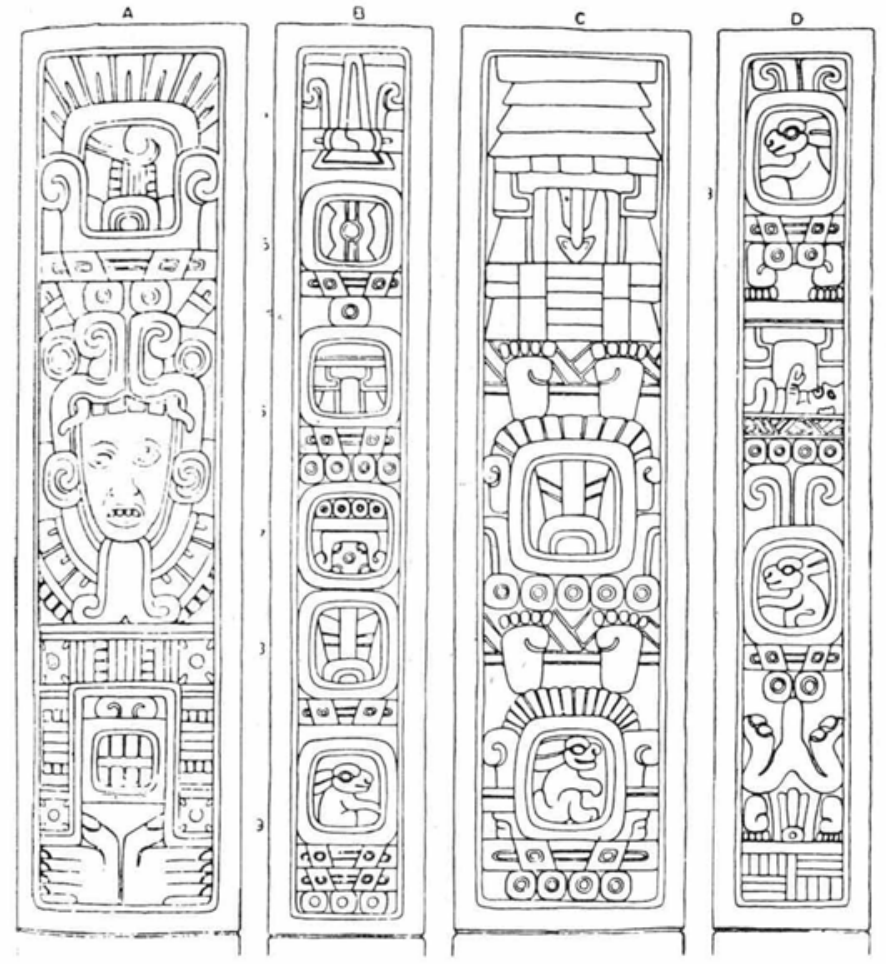

2. Xochicalco, Mor. A. Dibujo que reproduce el relieve del talud frontal del edificio principal, pirámide de las serpientes emplumadas.

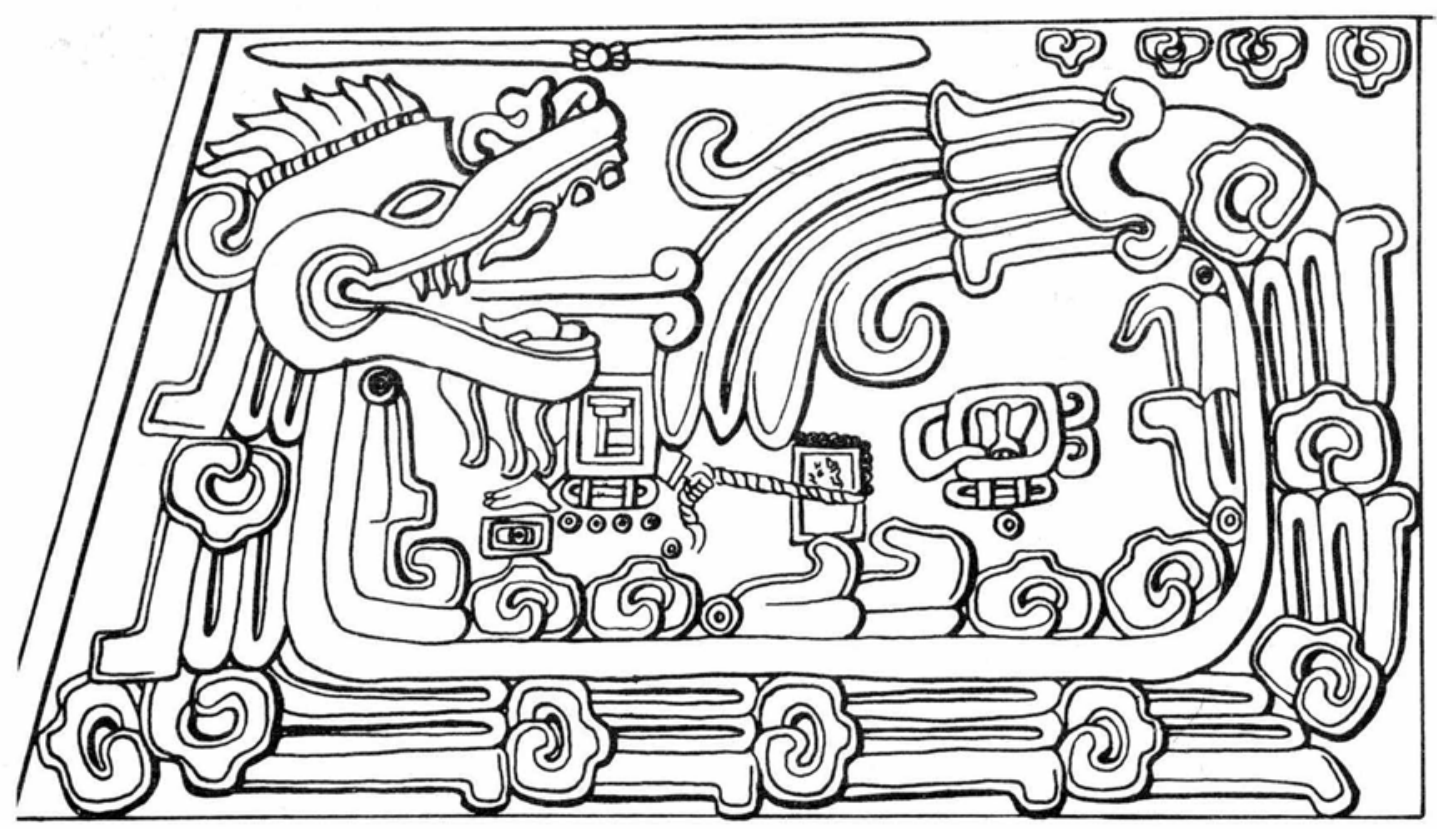

$2 B$. Dibujo de la estela 1, alusiva a la creación del dios Quetzalcóatl. 
DOI: http://dx.doi.org/10.22201/iie.18703062e.1989.60.1532

3A. Quetzalcóatl-Xolotl, relieve en piedra procedente de Tuxpan, Museo Nacional de Antropología.

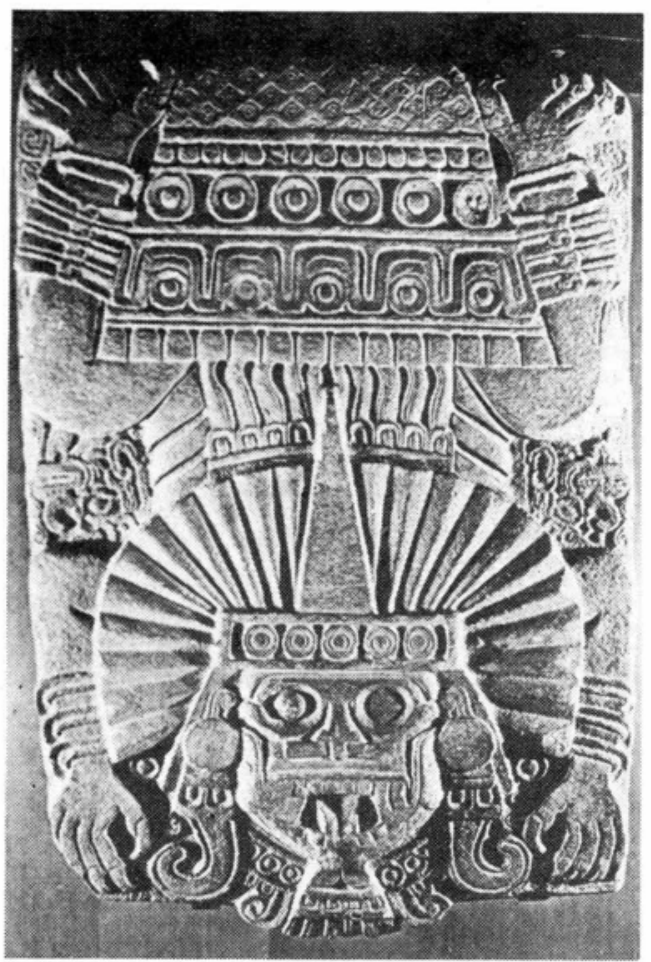

3B. Códice Borgia, página 73. representando a la dualidad Quetzalcóatl, con máscara de Ehecatl, (izquierda) y Mictlantecutli (derecha), dios de la región de los muertos.

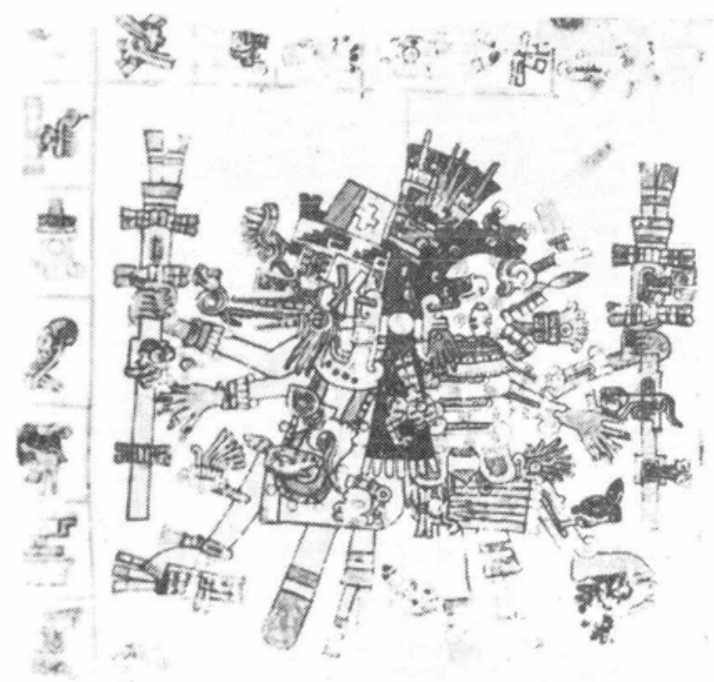


DOI: http://dx.doi.org/10.22201/iie.18703062e.1989.60.1532
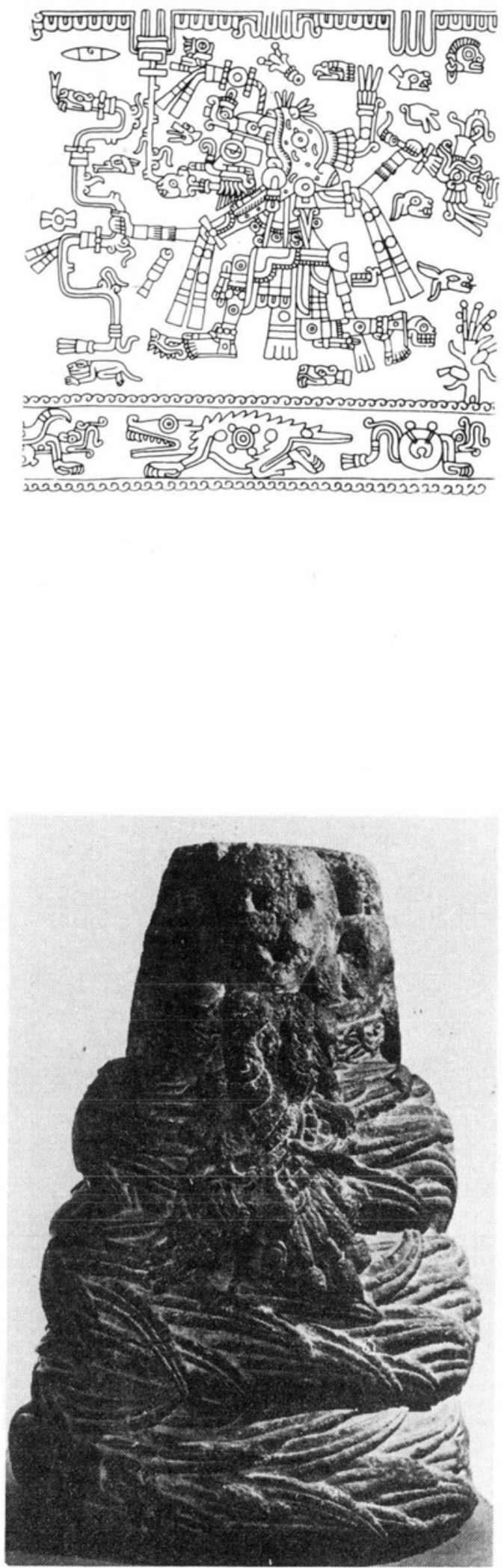

4A. Tláloc Barbado con la serpiente emplumada y los días del calendario; dibujo tomado del Códice Laud, página 4.

$4 B$. Serpiente emplumada con el rostro, desfigurado, de Quetzalcóatl entre las fauces, Mexica, Museo Nacional de Antropología. 
5. Quetzalcóatl, dos interpretaciones.

A. Códice Borbónico, página 22.

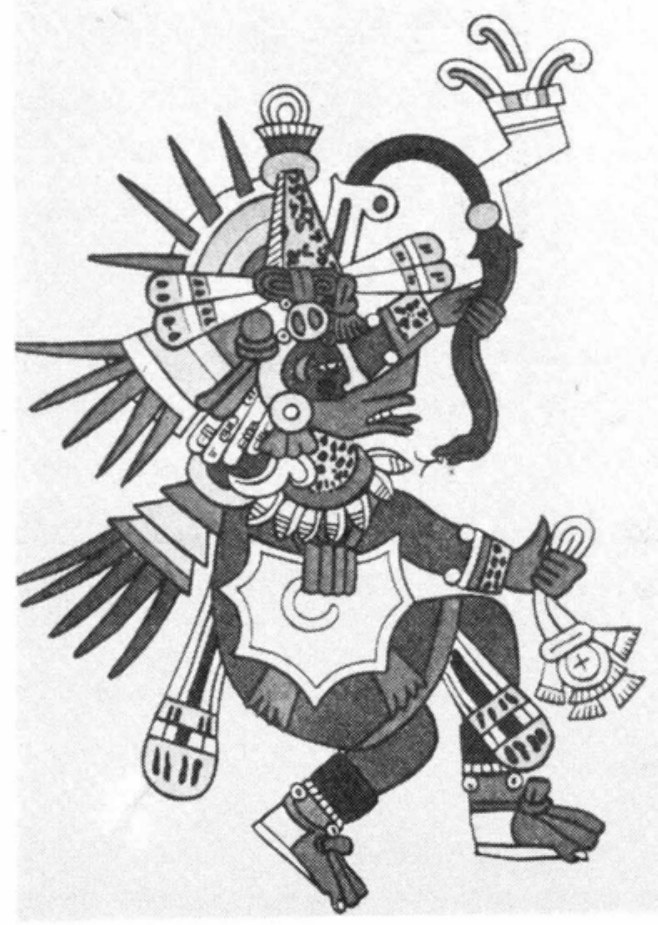

5B. Códice Florentino, libro I, lámina II, figura 5 , en este caso se trata del Sacerdote Ce-Acatl Topiltzin.

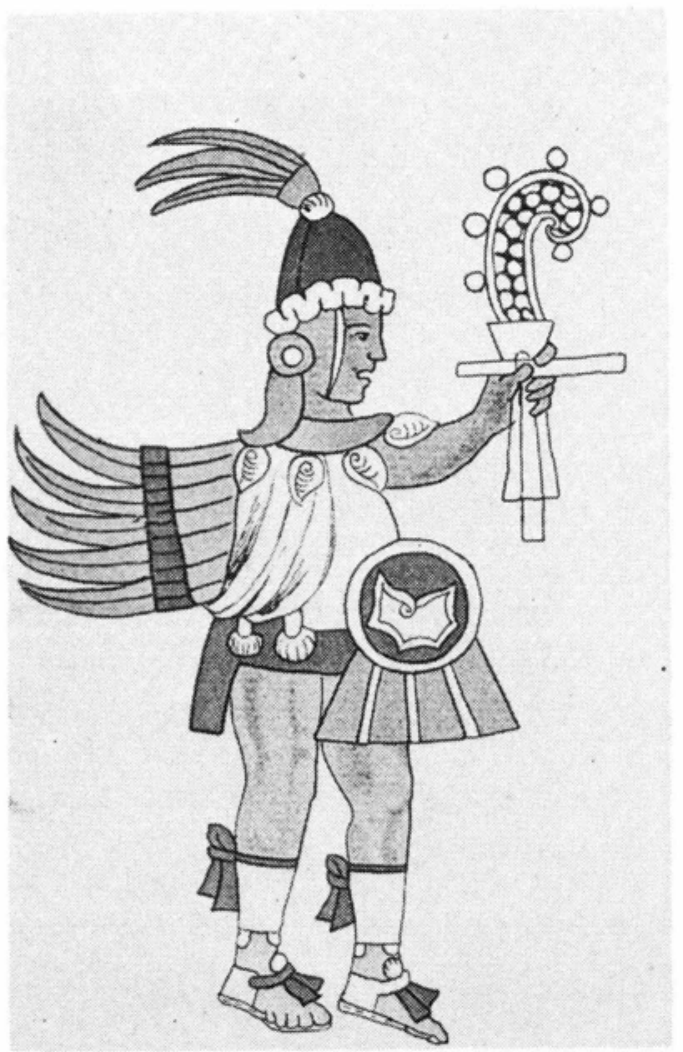


DOI: http://dx.doi.org/10.22201/iie.18703062e.1989.60.1532

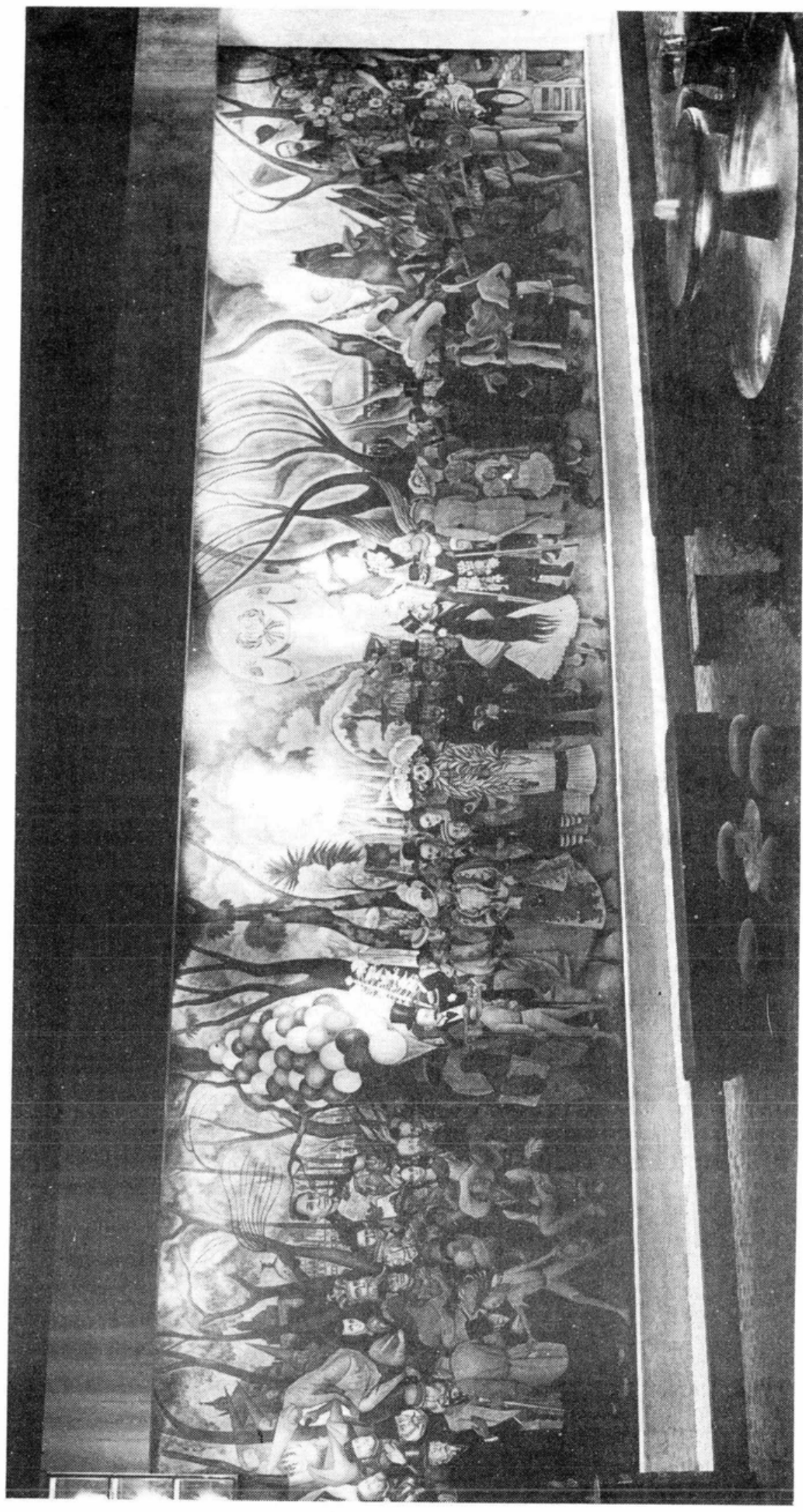

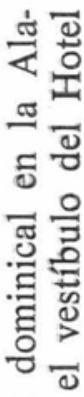

은

ఫ

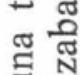

코

엉

옹 ญ

응

I

$\dot{\nabla}$

『ேं

¿

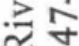

9

이 - 궁

要

엉 
DOI: http://dx.doi.org/10.22201/iie.18703062e.1989.60.1532

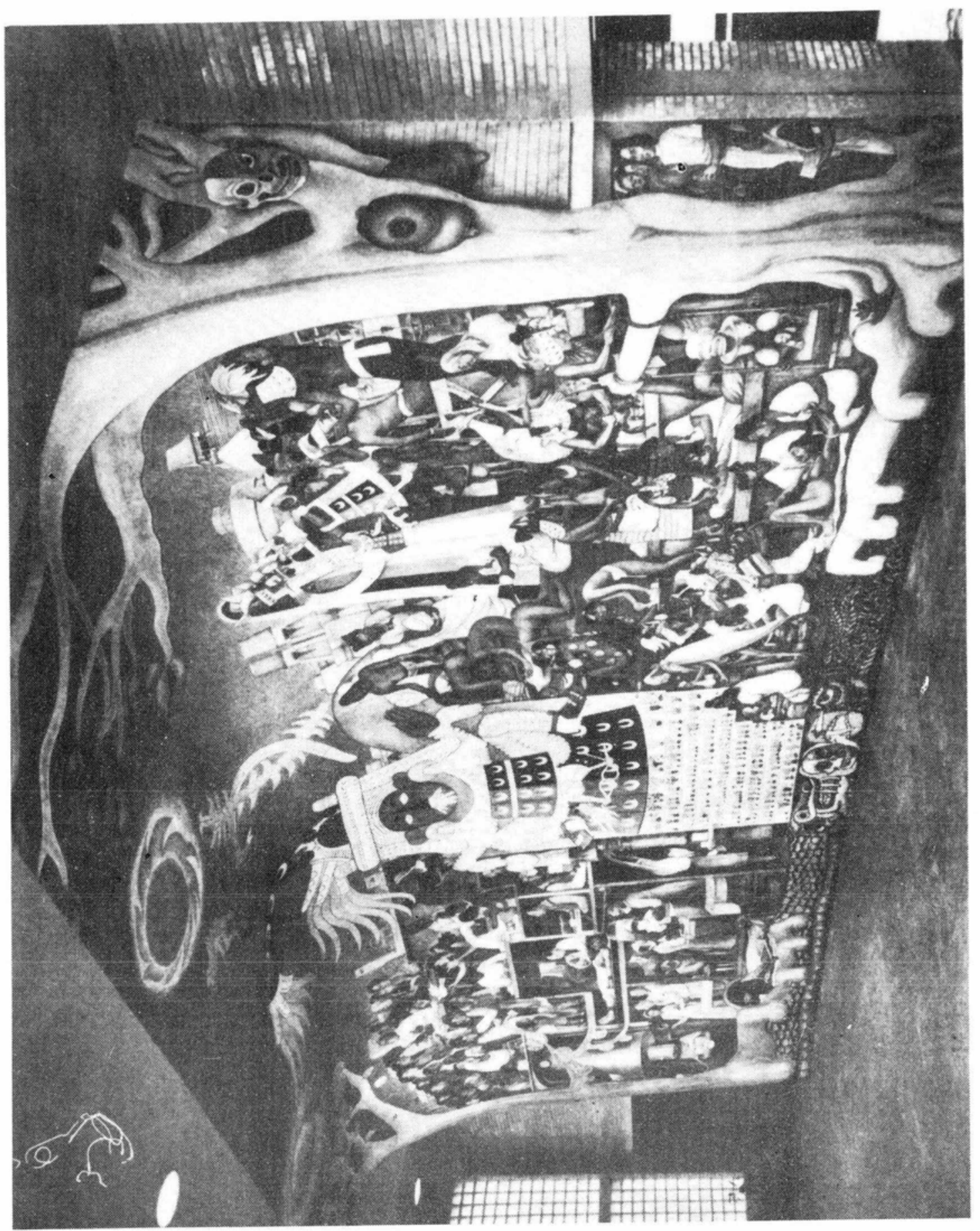

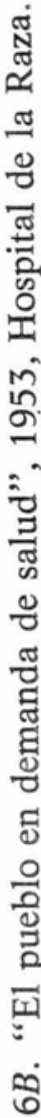


DOI: http://dx.doi.org/10.22201/iie.18703062e.1989.60.1532

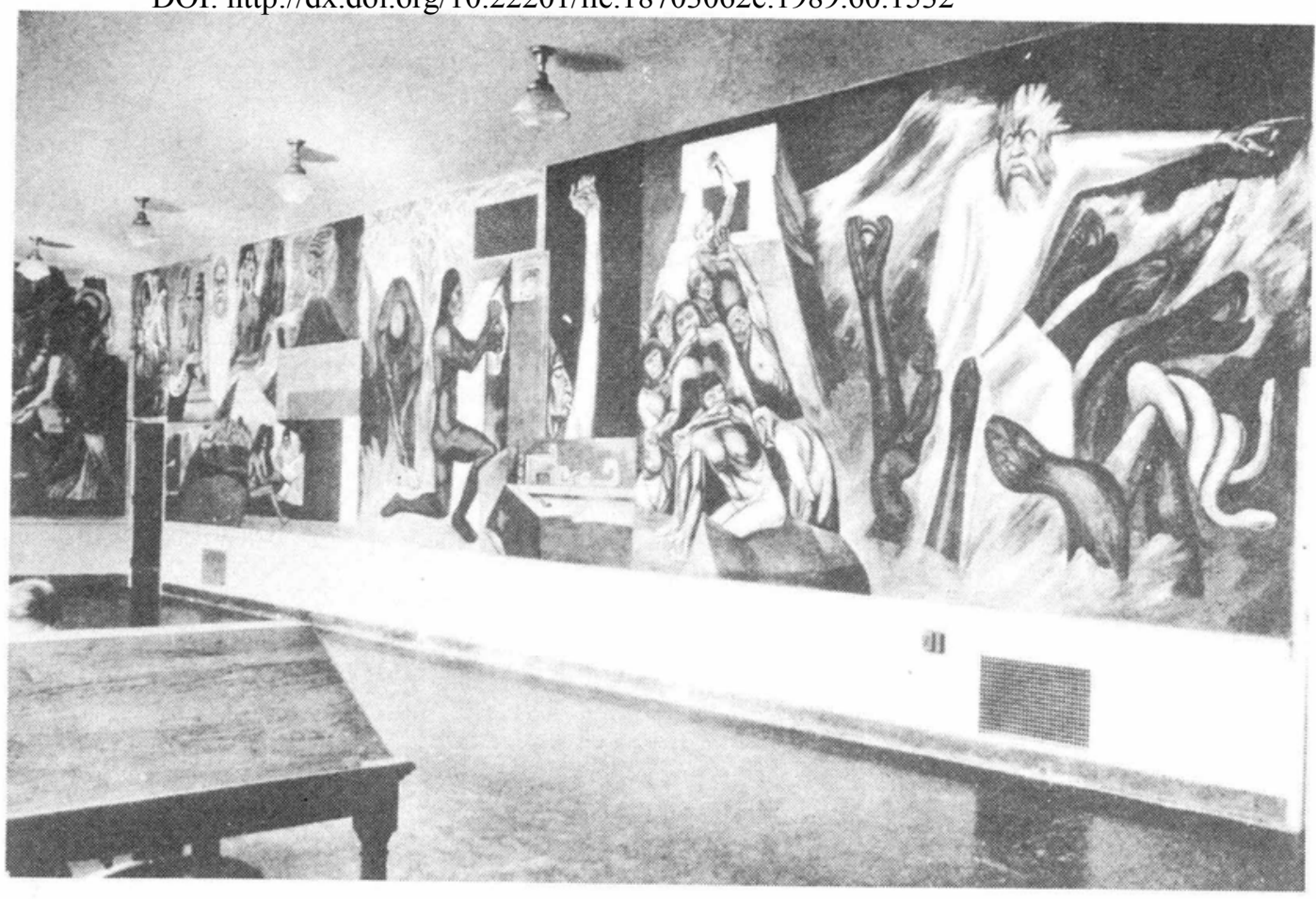

7. José Clemente Orozco, Biblioteca Baker, Darmouth College, 1932. A. El muro de la cultura indígena.

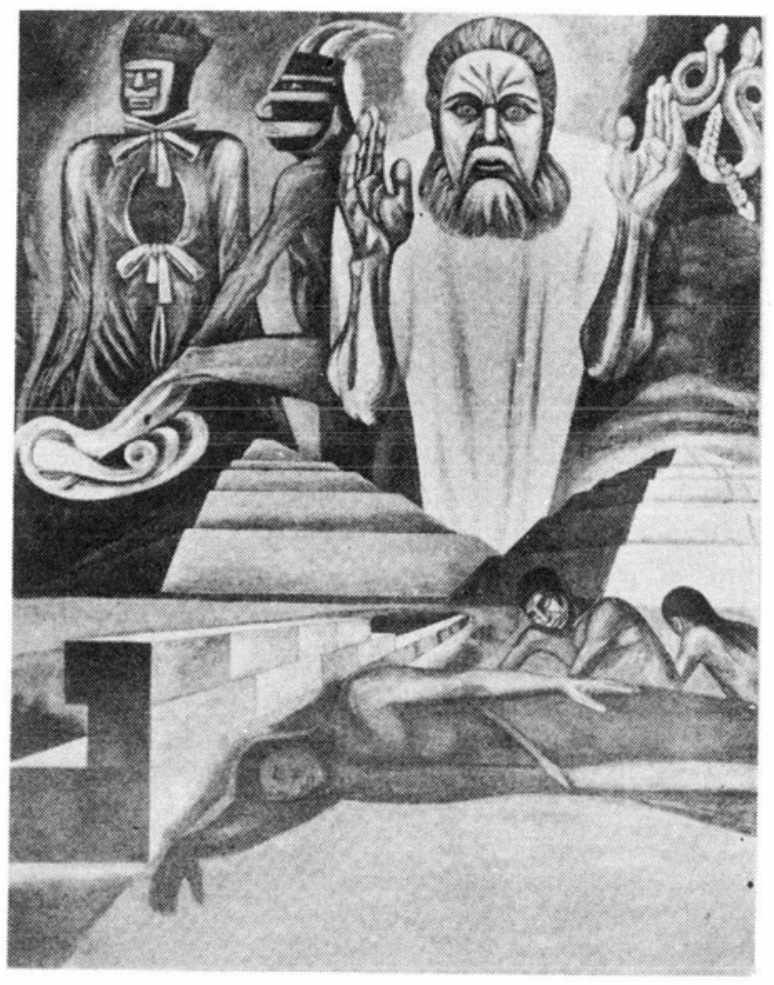

7B. "La llegada de Quetzalcóatl”, detalle. 
8. José Clemente Orozco. A. Biblioteca Baker, Darmouth College, 1932, "La partida de Quetzalcóatl”, detalle.

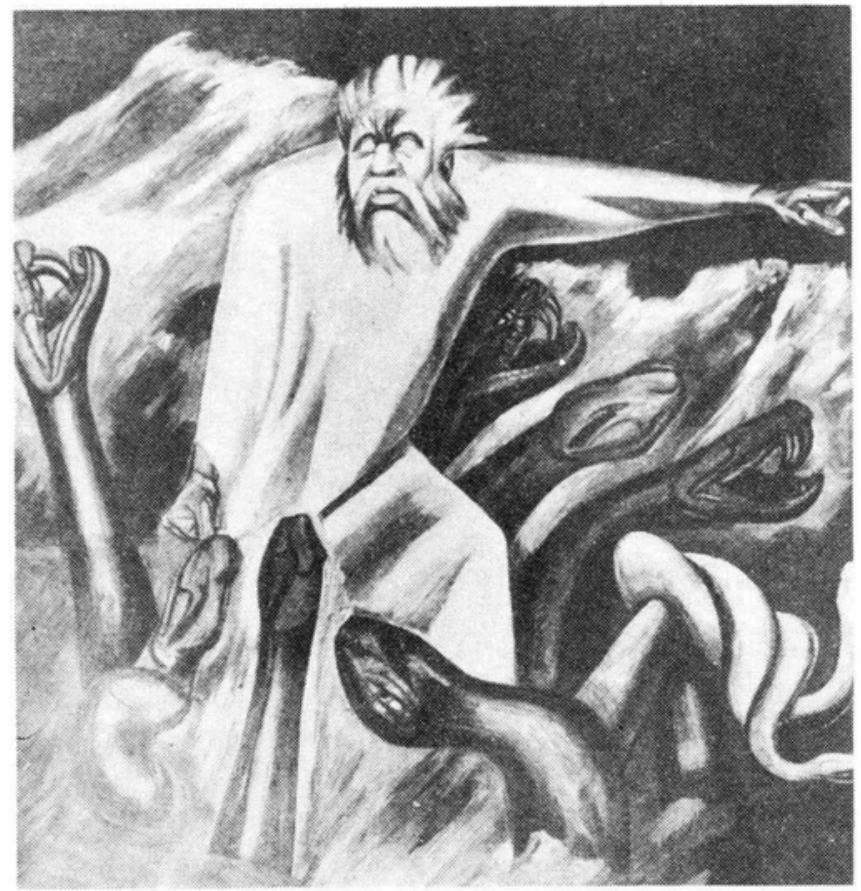

8B. Cabeza de Quetzalcóatl, lápiz 1932, Colección Museo de Arte Moderno, Nueva York. N. Y.

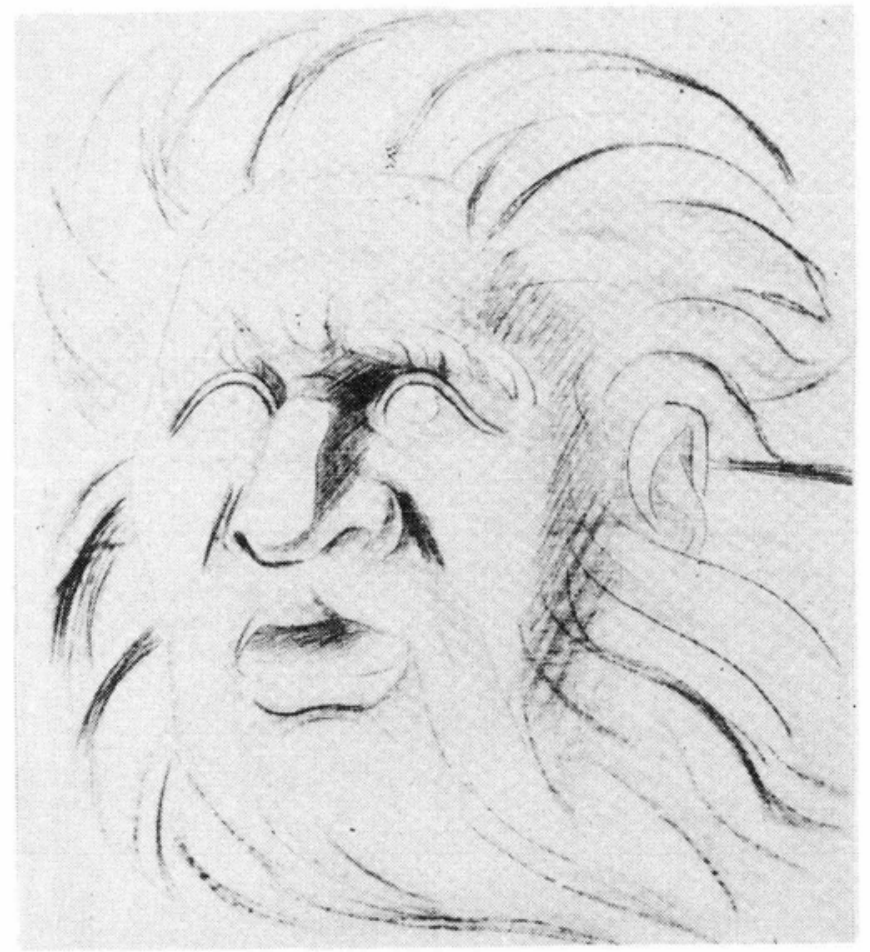


DOI: http://dx.doi.org/10.22201/iie.18703062e.1989.60.1532

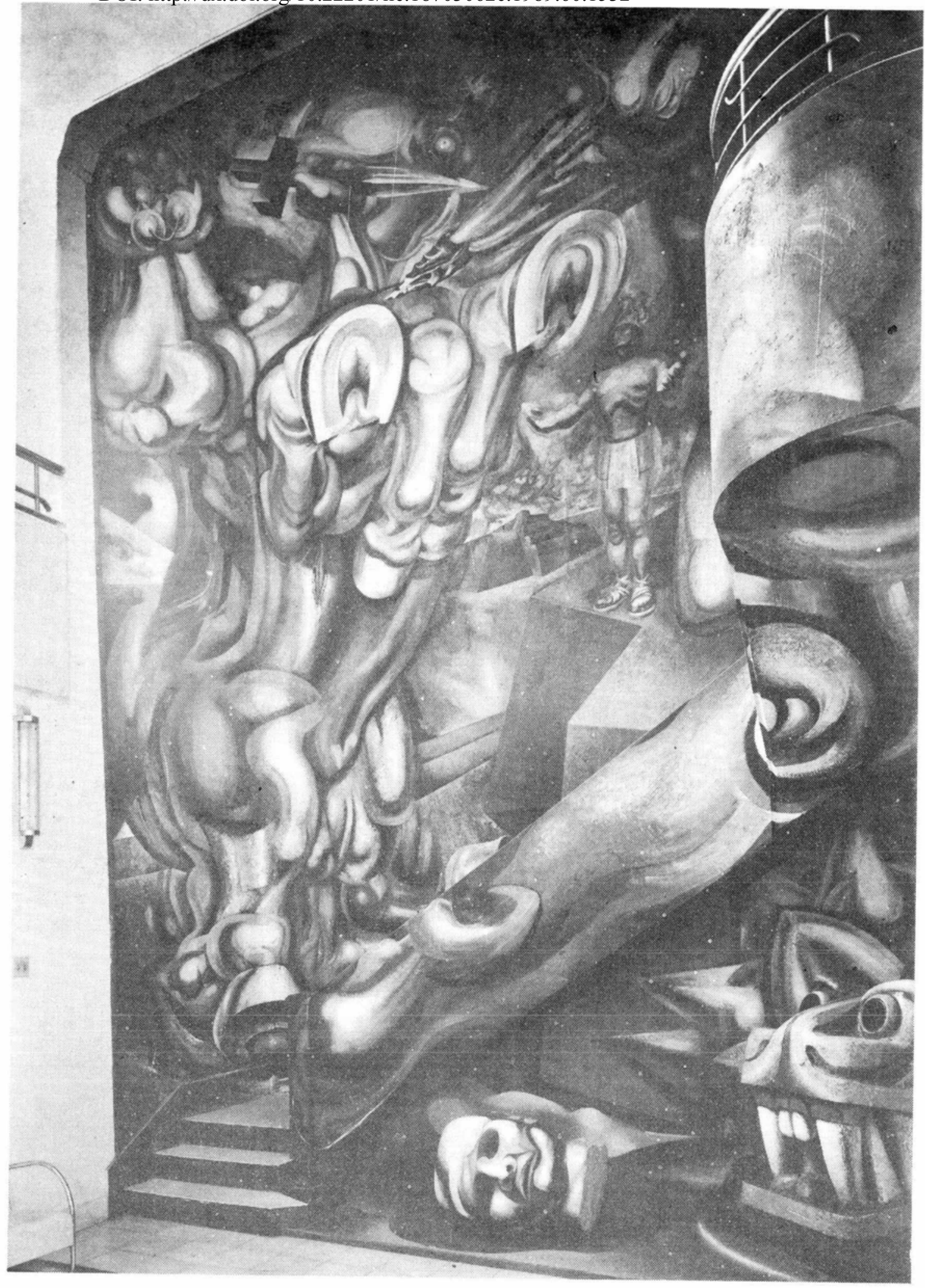

9. David A. Siqueiros, "Cuauhtémoc contra el mito", 1944, en su localización original en una casa particular en Sonora No. 9. 


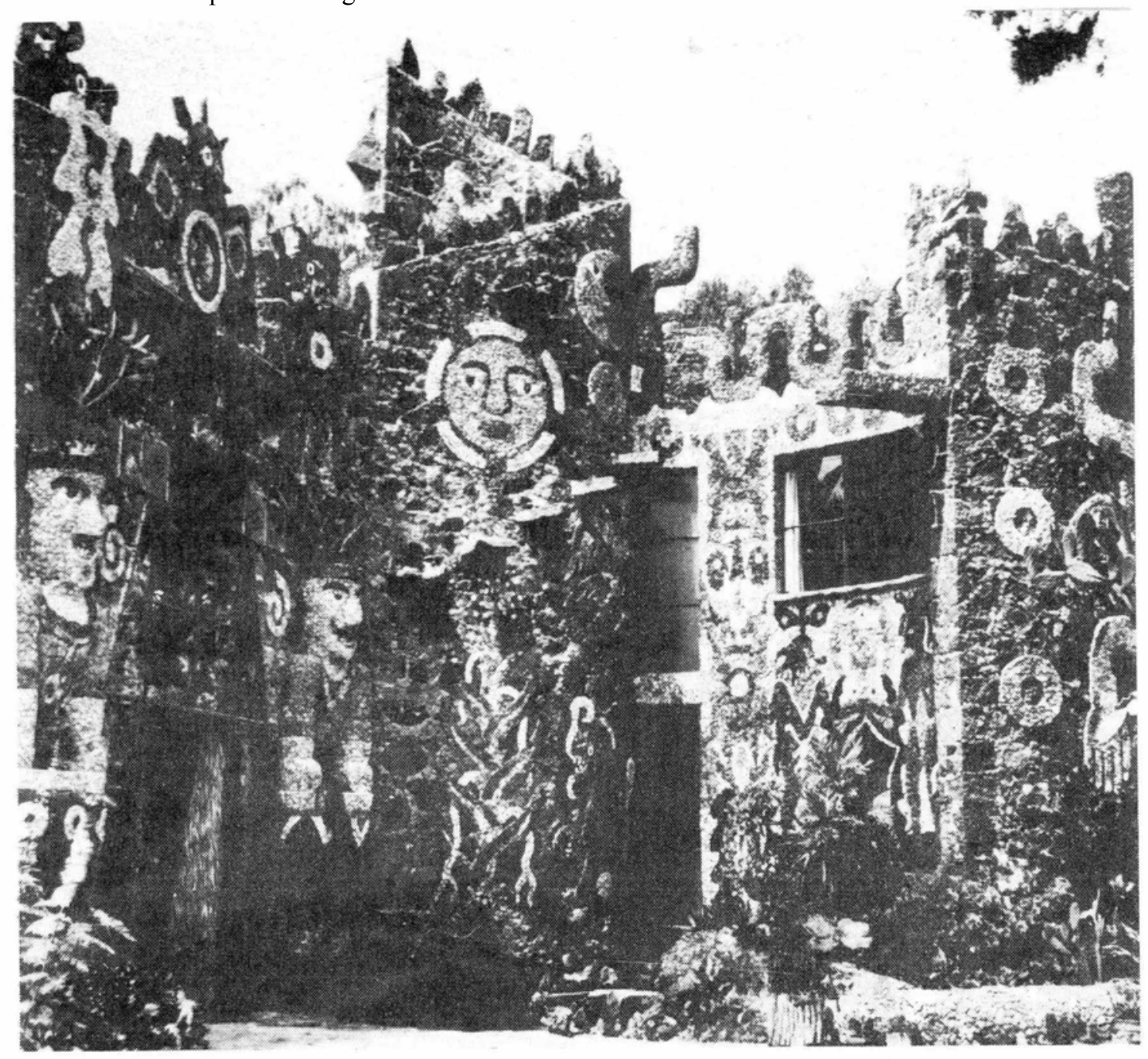

10. Juan O’Gorman, "Dioses y símbolos del México antiguo”, 1955, decoración en mosaico de piedras en su propia casa, Av. San Jerónimo No. 162. Actualmente destruidos. 
DOI: http://dx.doi.org/10.22201/iie.18703062e.1989.60.1532

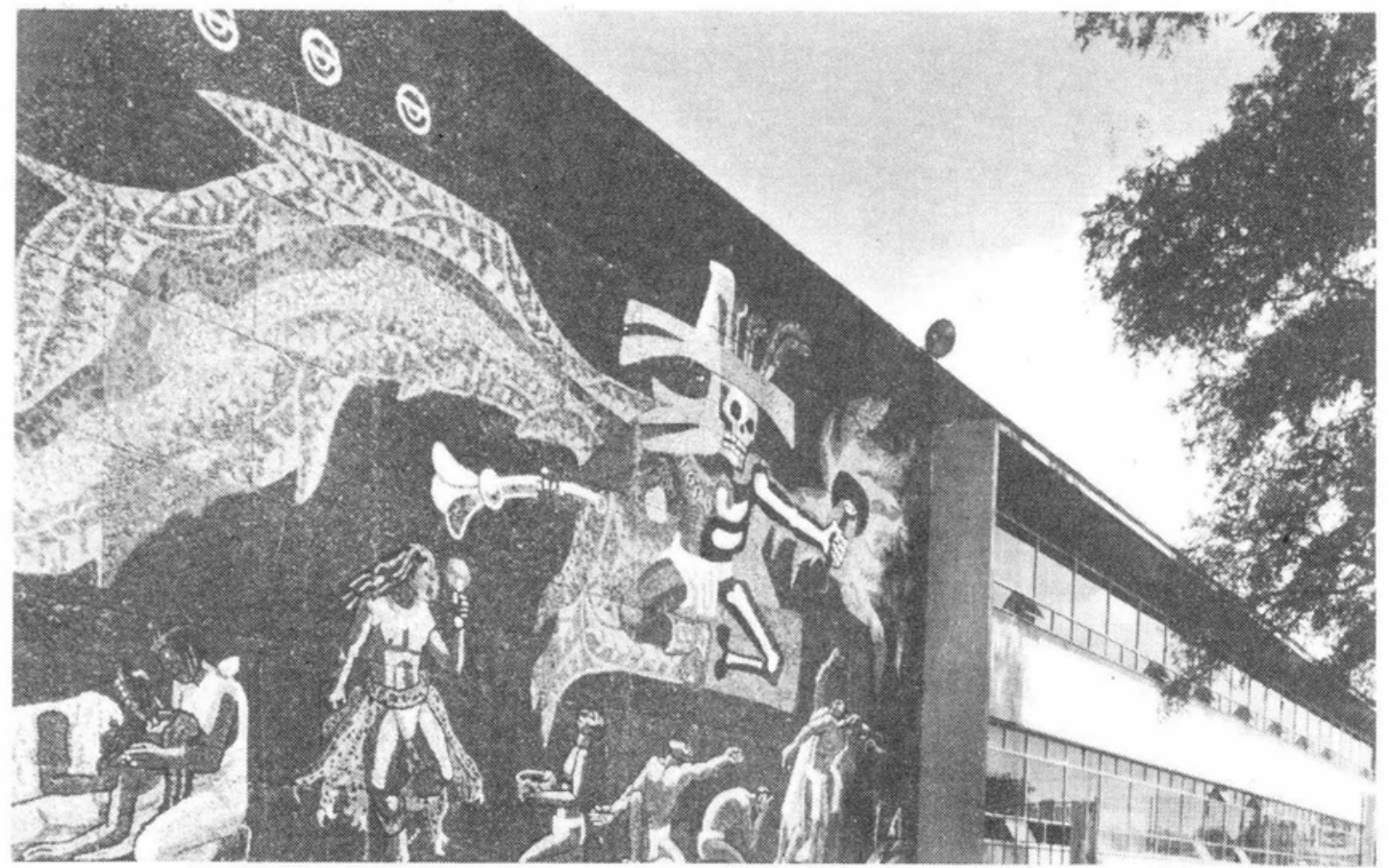

11. José Chávez Morado. A. "La magia y las ciencias médicas”, Mural en mosaico al exterior de los laboratorios CIBA.

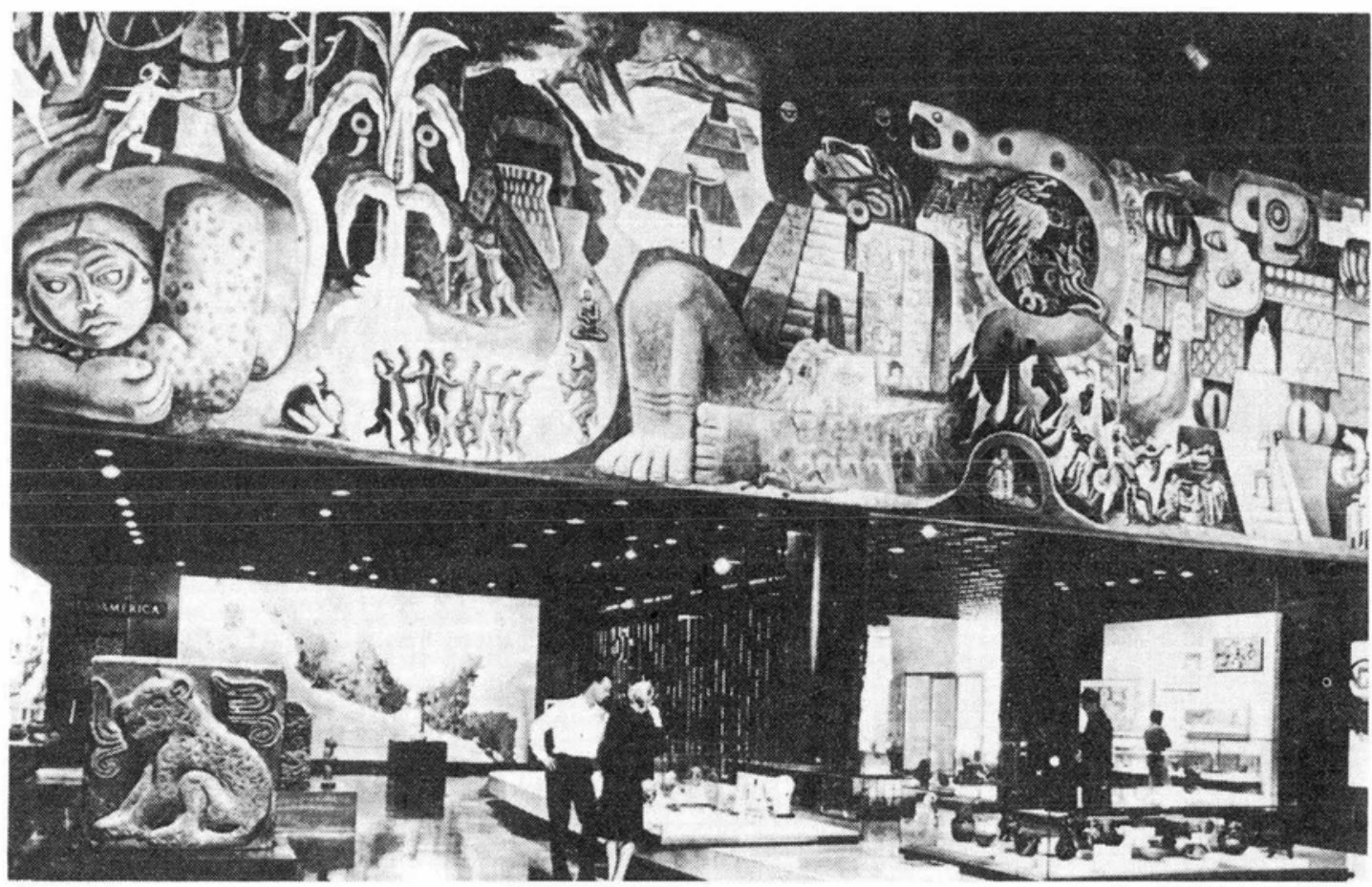

11B. “Expresión cultural de Mesoamérica”, 1954, Museo Nacional de Antropolología, Sala Mesoamericana. 
12A. Rodrigo Arenas Betancourt, "Prometeo", 1952, actualmente localizado en la nueva Facultad de Ciencias, Ciudad Universitaria, UNAM.
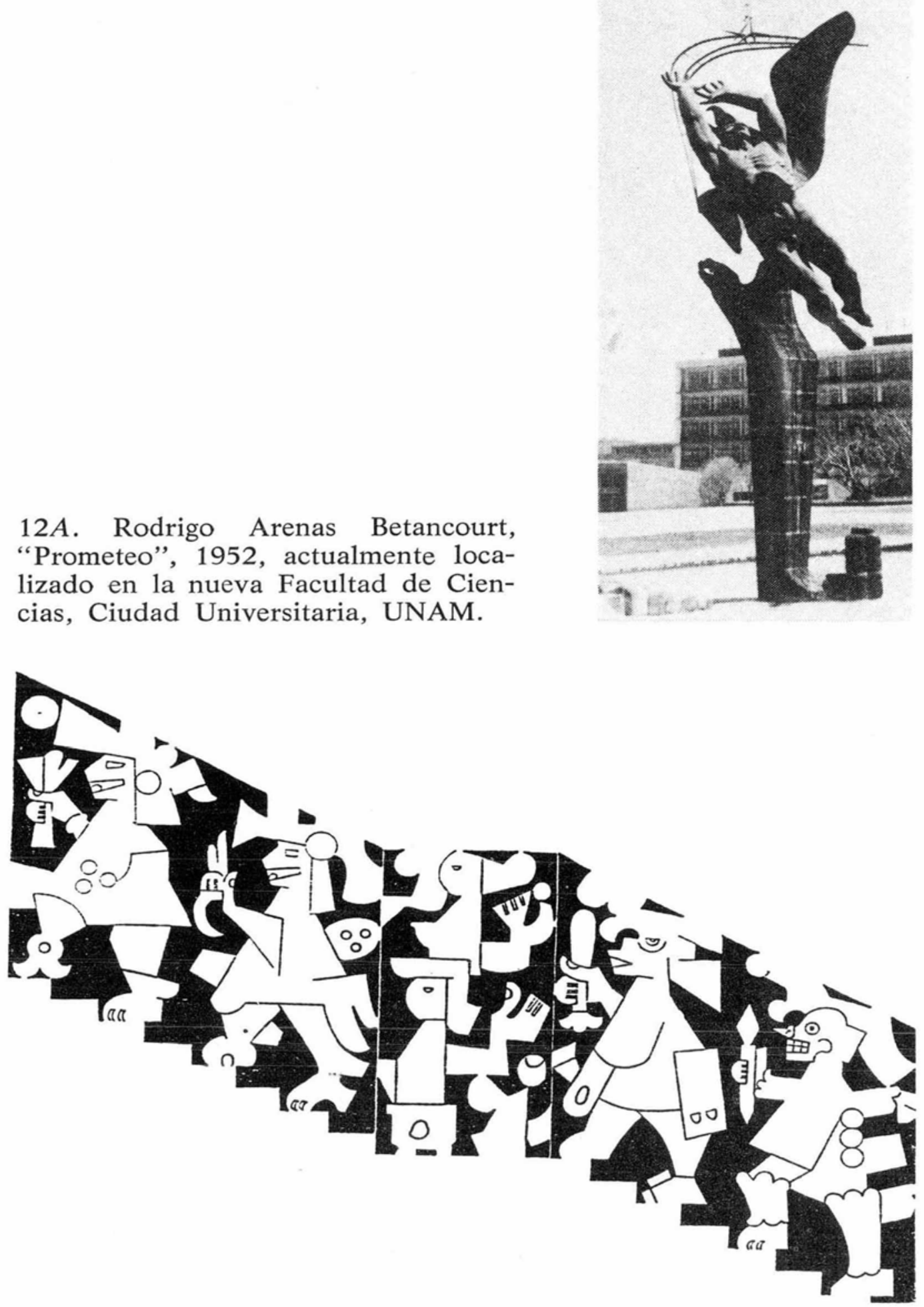

12B. Carlos Mérida, dibujo de la decoración en relieve de concreto para las escaleras del edificio I de la Unidad Habitacional Benito Juárez. Actualmente destruida; Quetzalcóatl es el segundo personaje de derecha a izquierda. 


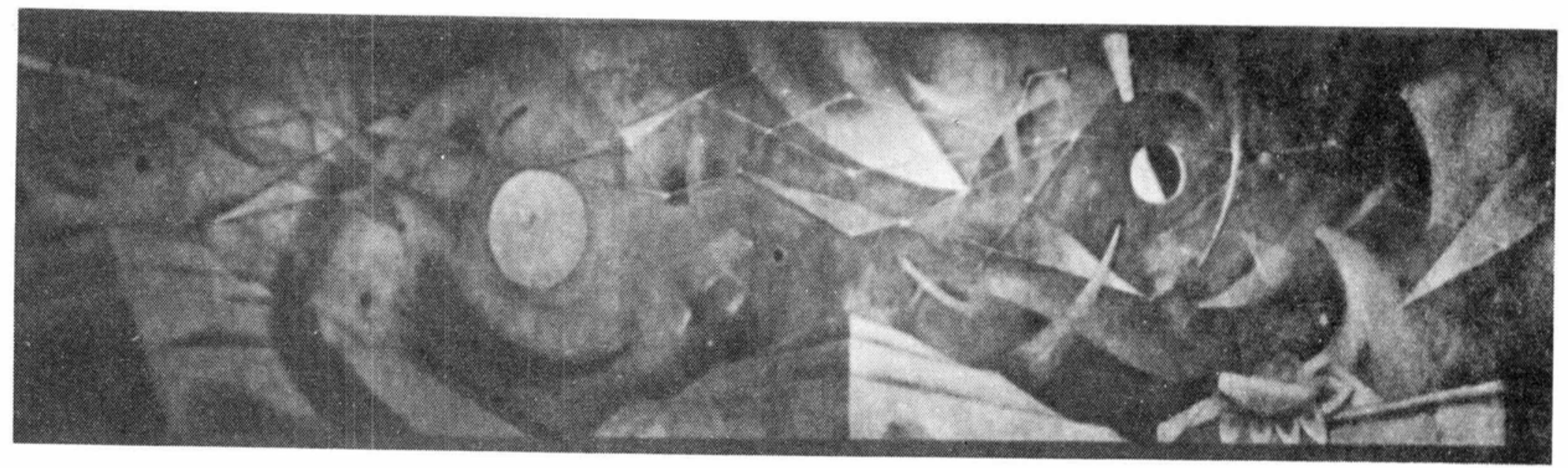

13. Rufino Tamayo. A. "El día y la noche", 1954, Mural en vinilita pintado originalmente para la droguería del almacén "Sanborn's Reforma". 
DOI: http://dx.doi.org/10.22201/iie.18703062e.1989.60.1532

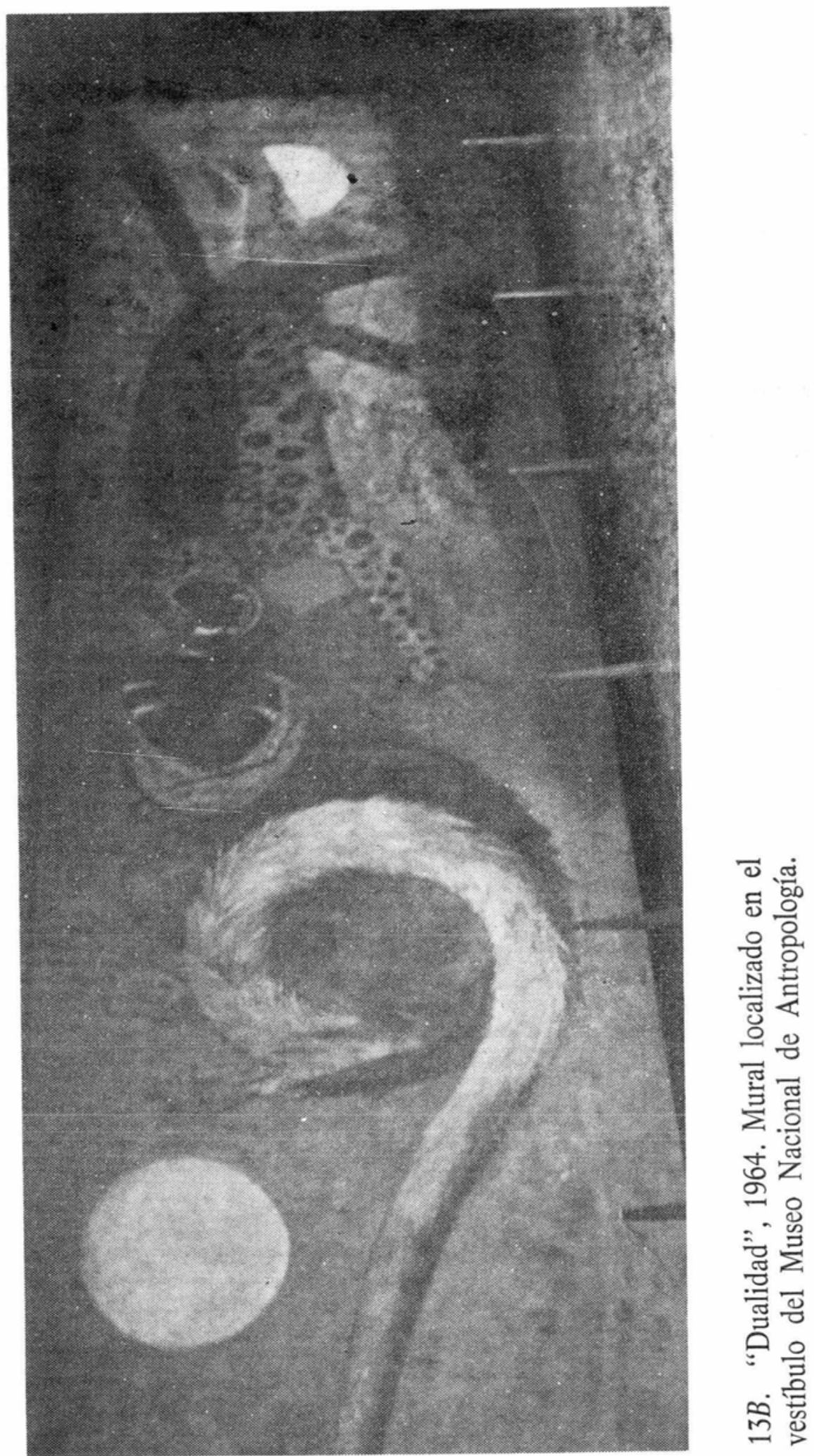




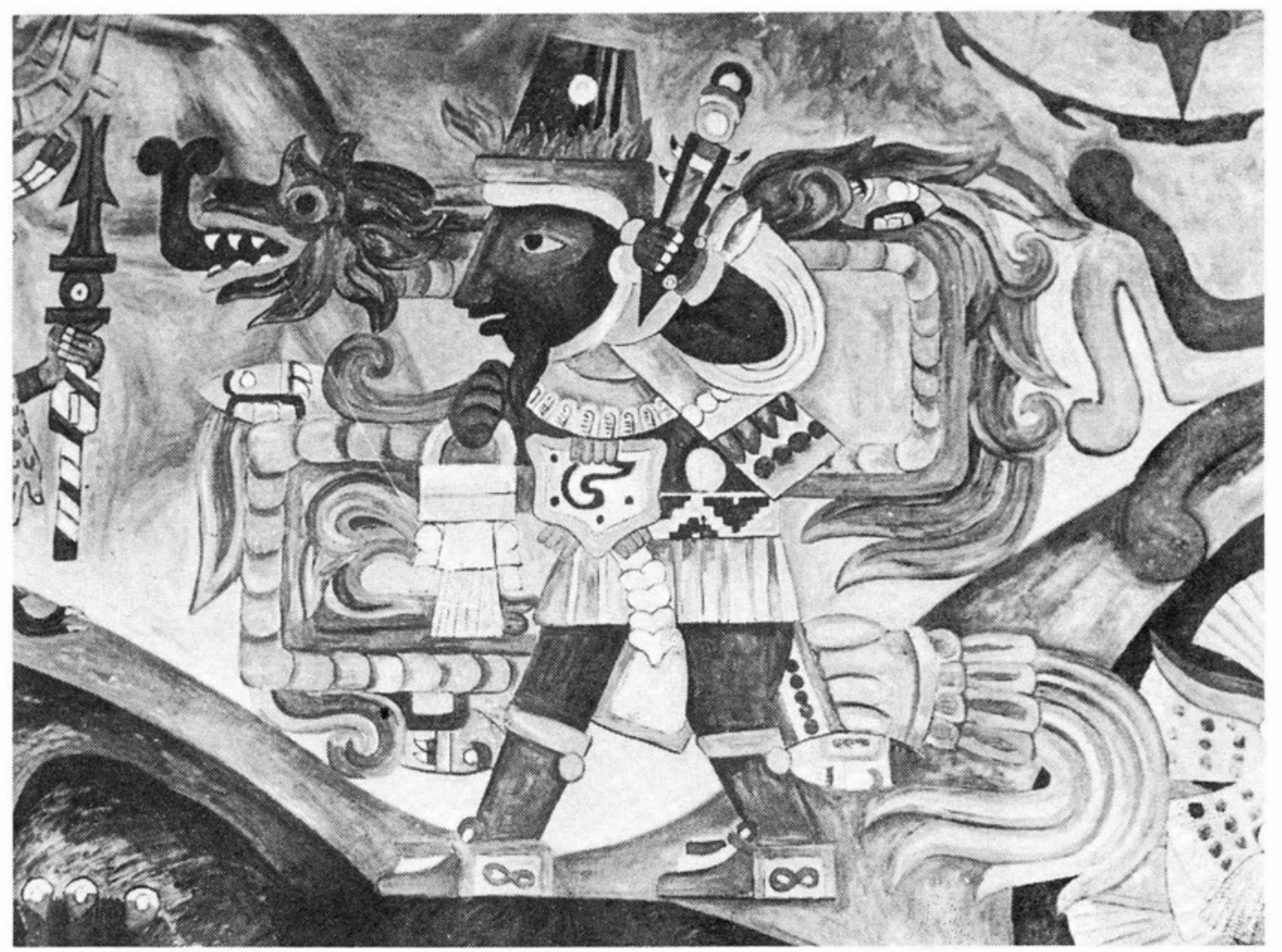

14. Raúl Anguiano, detalle del mural. "Deidades de Mesoamérica”, 1966. Sala Mesoamericana, Museo Nacional de Antropología. 


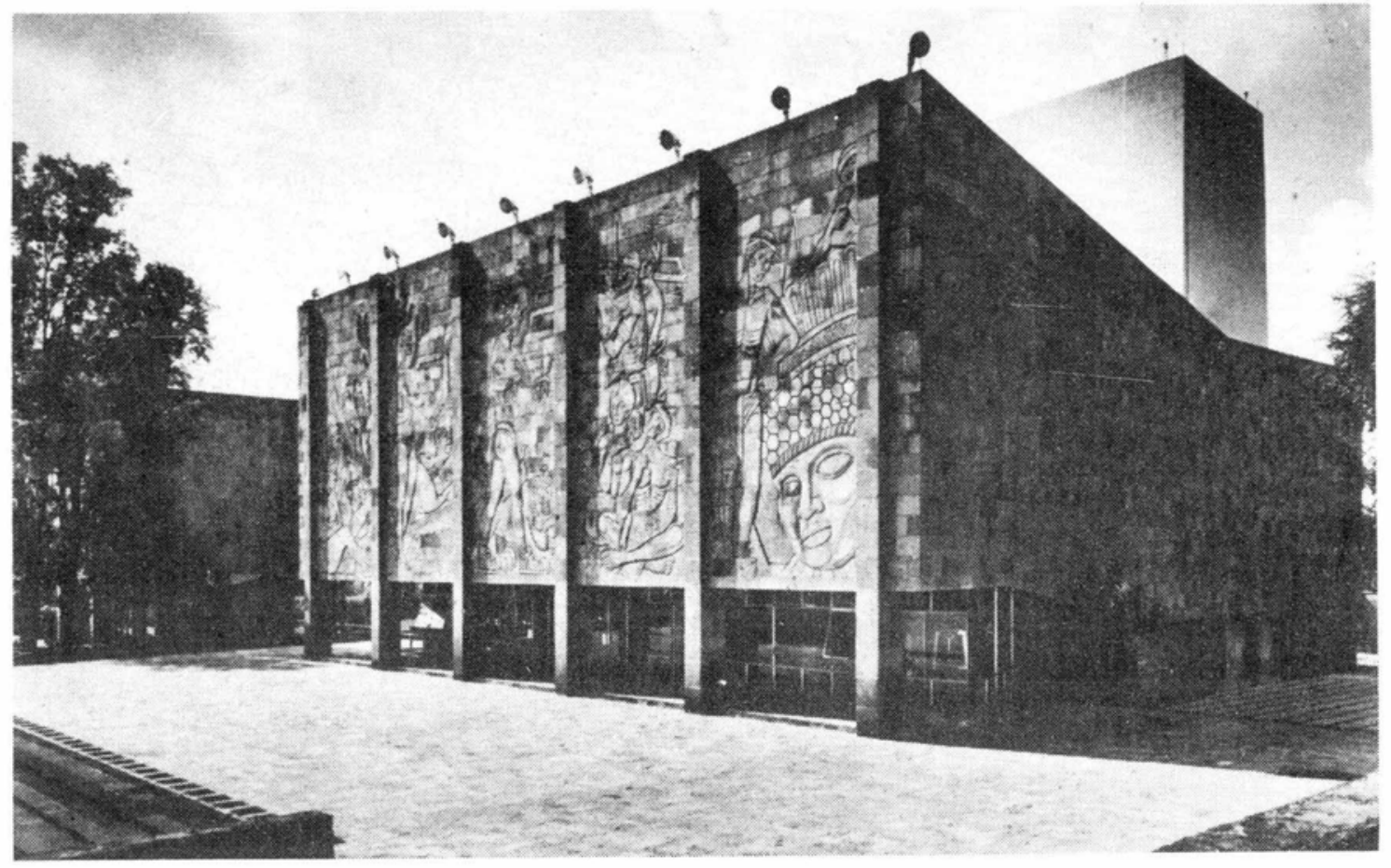

15A. Federico Cantú, "Cultura Tolteca”, 1960, relieve en el frontispicio del Teatro de la unidad habitacional Independencia, Arq. Alejandro Prieto.

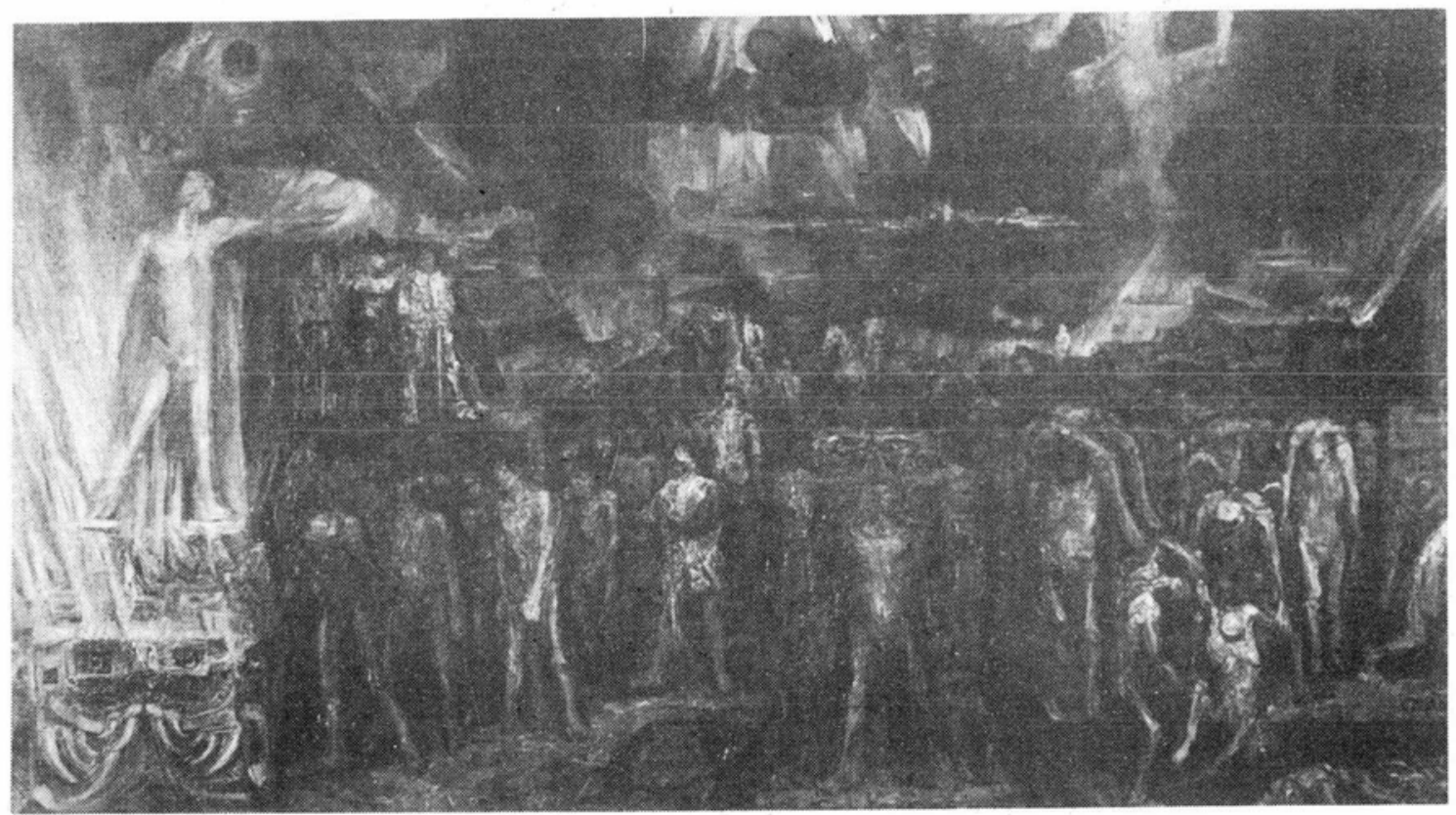

15B. Francisco Moreno Capdevila, "Conquista, y destrucción de Tenochtitlán”, 1964, Museo de la Ciudad de México. 
DOI: http://dx.doi.org/10.22201/iie.18703062e.1989.60.1532

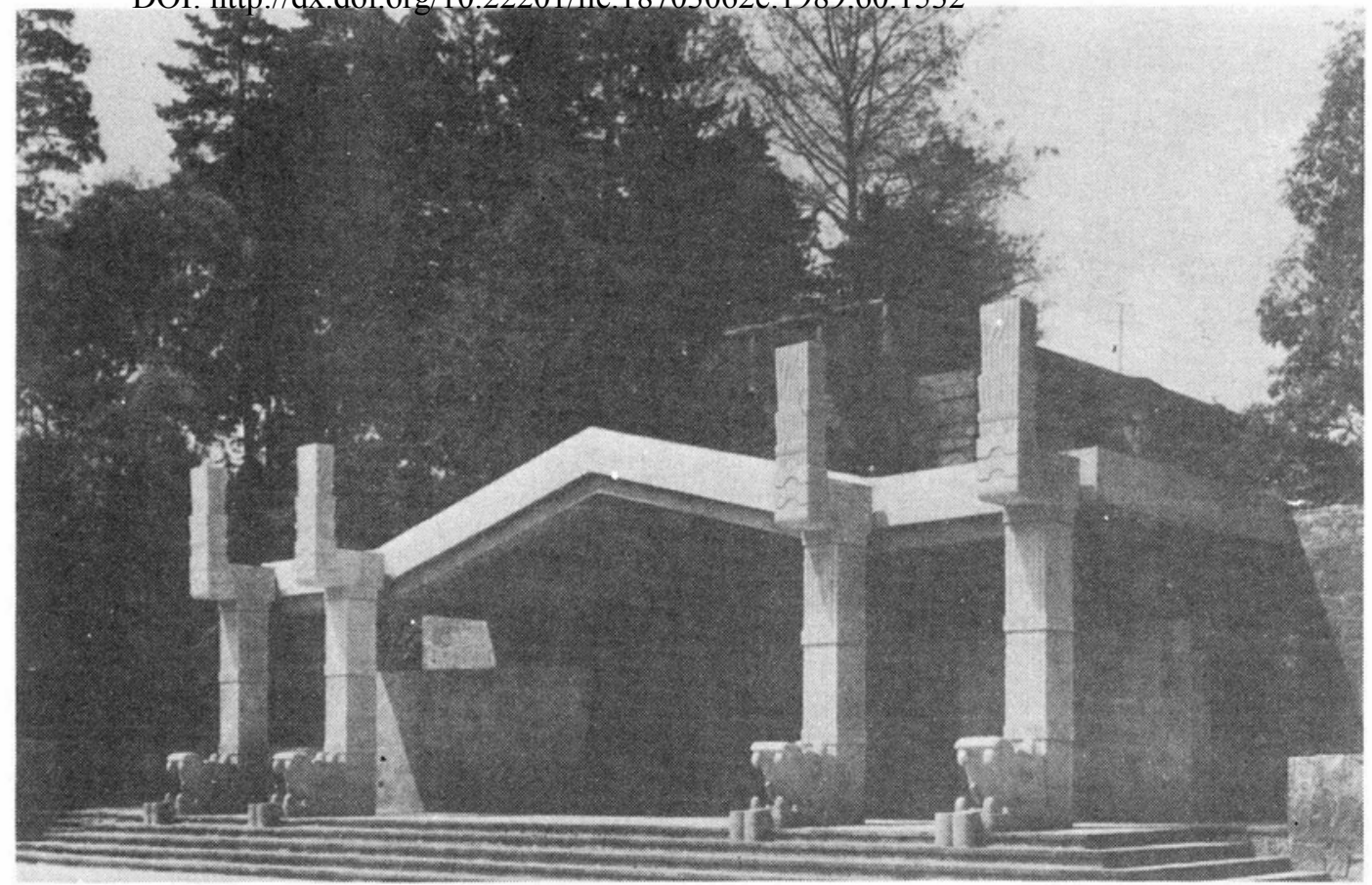

16. Luis Ortiz Monasterio. A. Teatro al aire libre en la Unidad Habitacional Independencia, con cuatro columnas serpentinas.

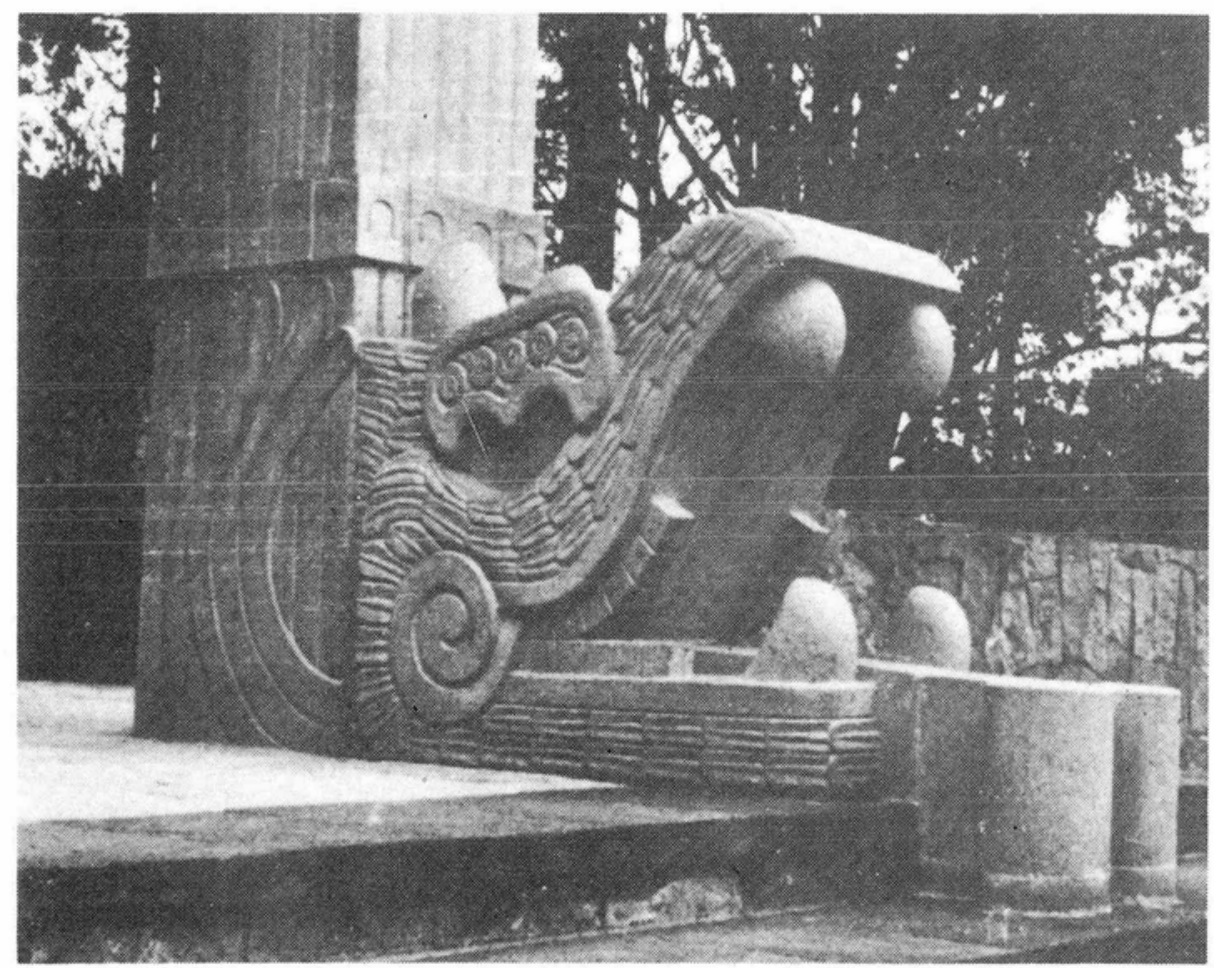

16B. Detalle de una columna. 
recientes. Es el caso de Federico Cantú, quien en dos obras en bajo-relieve en piedra talló la imagen de Ce-Acatl Topiltzin, gobernador sabio en actitud de maestro; la primera trata de la "Cultura tolteca", 1960, y se localiza en el frontispicio del teatro de la Unidad Habitacional Independencia. En la segunda, el tema escogido es "Quetzalcóatl y Venus impartiendo sus conocimientos al pueblo tolteca", 1962, y estaba situado en el que fuera Hospital de Pediatría del desaparecido Centro Médico Nacional, ambas en la ciudad de México.

En la misma Unidad Independencia, Luis Ortiz Monasterio realizó una serie de esculturas en piedra con el tema mesoamericano de Quetzalcóatl, durante 1964, y se localiza en el núcleo central del conjunto. Cuatro columnas serpentinas, inspiradas en las que flanquean el acceso al templo de los guerreros en Chichén Itzá, sostien la cubierta del escenario de un teatro al aire libre. Frente al acceso a la explanada donde se emplaza dicho escenario, se encuentran sendas esculturas de la serpiente emplumada. La srimera representaba al ofidio, replegado sobre sí mismo conformando un olumen vertical. Cercana está la figura de otra serpiente emplumada que isa su cabeza sobre el hombro de un sacerdote-Quetzalcóatl, tomado del dice Florentino; ${ }^{23}$ esta última pieza es la más interesante por la comsición dual en la que contrasta el movimiento de la serpiente con el hieratismo del personaje mitológico, hombre blanco y barbado.

Por su parte, Francisco Moreno Capdevilla, en el mural "Conquista y destrucción de Tenochtitlan", 1964, localizado en el Museo de la Ciudad de México, aporta una personal versión del tema; a la izquierda de su visión apocalíptica de la caída del reino mexica, surge Quetzalcóatl redivivo, quien entre llamas y sobre un monolito con su efigie ofidiana protege a quienes realizaron la conquista.

Para finalizar esta revisión de representaciones actuales de la leyenda del hombre-dios Quetzalcóatl, que no pretende ser exhaustiva, está Luis Covarrubias; este artista realizó en 1964, en la sala de Etnografía del Museo Nacional de Antropología, un "Mapa general" de Mesoamérica, en el cual, a la manera de los mapas de su hermano Miguel, pintó sobre la orografía de la República Mexicana los principales monumentos prehispánicos. Además incluyó una serie de dioses, entre los que reconocemos a Ehécatl con su máscara de ave y a Kukulkán llegando a tierras yucatecas.

23 El Códice Florentino sirvió de inspiración para el aspecto general de este personaje, aunque en este caso lleva una barba y una serpiente a manera de cinturón como rasgos diferentes. 
Como se ha mencionado, éstos son los principales ejemplos de la iconografía de Quetzalcóatl en nuestro siglo, aunque cabe mencionar que se han dejado de lado ciertas representaciones que no alcanzan verdadera calidad artística. Este sería el caso de una fuente situada en el interior del fraccionamiento Jardines del Pedregal de San Ángel, o el de un monumento dedicado al mítico dios, en la avenida Luis Cabrera, en San Jerónimo. Asimismo se han omitido obras relacionadas con el mito, porque no corresponden a sus representaciones; aquí se hubiesen podido incluir la fuente de Tláloc en Chapultepec, 1951, de Diego Rivera, o las serpientes del Pedregal de Mathias Goeritz, 1951, y de Federico Silva, 1986, entre otros. Se trata de un buen número de obras que, si bien están relacionadas con el dios mesoamericano, no forman parte de su iconografía.

$\mathrm{Al}$ analizar globalmente estas expresiones artísticas se pueden definir tres posiciones diferentes. La primera es aquella que toma a la serpiente emplumada como un elemento decorativo con connotaciones de mexicanidad. Es el caso de las últimas obras de Diego Rivera o de la de Rufino Tamayo en el mural de Houston, donde las figuras ofidianas son una simple referencia al pasado prehispánico; también Luis Covarrubias puede integrarse a esta expresión meramente ornamental. La segunda es aquella en la que los artistas, inspirándose en la iconografía precortesiana, incluyen al hombre-dios como parte de su discurso narrativo. En algunas ocasiones Quetzalcóatl tiene un papel central en la composición, como en el mural exterior de los laboratorios CIBA, donde José Chávez Morado circunscribe el diseño a la dualidad Quetzalcóatl-Mictlantecutli; también se da el caso de que el personaje mitológico forme parte menor de un conjunto pictórico, tal y como sucede en la obra de Juan O'Gorman en la biblioteca de Ciudad Universitaria, o en el mural de las escaleras de Palacio Nacional de Diego Rivera.

Sin embargo, las verdaderas aportaciones en el campo del arte son aquellas en que sus autores, conociendo la leyenda y aun las imágenes prehispánicas, las toman como un punto de partida para expresar sus ideas y sentimientos al respecto, logrando obras de gran fuerza y originalidad. En esta tercera posición, José Clemente Orozco juega un papel preponderante con la terrible personificación de Ce-Acatl Topiltzin, quien, como todos los personajes que pintó, conmueve a propios y extraños. Rufino Tamayo, en "Dualidad", logra esta singularidad, al plasmar en tan sólo dos figuras, la serpiente-día y el tigre-noche, toda la carga antagónica del mundo precortesiano. Asimismo son de mencionar la particular visión de Carlos Mérida, quien con un vocabulario propio se ocupa del pasado indígena, 
así como la de Luis Ortiz Monasterio, que supo imprimir en su sacerdotedios la dignidad e intemporalidad de su cargo. En estos ejemplos es donde toma vida nuevamente entre nosotros el mito de Quetzalcóatl.

Asimismo, al observar la sucesión temporal de estas obras es posible corroborar la liga que existe con la expresión de sentimientos nacionalistas. Efectivamente, en el movimiento conocido como Escuela Mexicana de Pintura, surgido de la Revolución, aparecieron las primeras presentaciones del hombre-dios: y en la cuarta y quinta década de este siglo, cuando e] gobierno revolucionario se institucionaliza y auspicia las expresiones artísticas que le son afines, el muralismo de mensaje nacionalista tiene gran auge. Posteriormente este impulso se diluye, a partir de un compás de espera en la integración plástica, y será tan sólo en la séptima década, con la construcción de importantes edificios públicos, cuando la integración plástica resurja, imbuida del mismo espíritu nacional.

De este modo se puede explicar la cronología y el agrupamiento de las obras revisadas, que en su mayoría son públicas, por lo que la incidencia del contexto histórico es mayor. Asimismo, una ausencia de este tipo de expresiones, tanto por la caducidad del movimiento muralista como por un deseo oficial de integración al mundo del desarrollo, han cancelado en la actualidad una expresión nacionalista de raíces prehispánicas; esto sin olvidar que las tendencias contemporáneas, alejadas de la figuración, coadyuvan a la carencia de representaciones del mundo mesoamericano entre las nuevas generaciones de artistas.

Quetzalcóatl, sin embargo, sigue siendo un ser mitológico con gran atractivo para el estudioso, por lo que encierra de misterio y riqueza iconográfica. Los textos contemporáneos han buscado dilucidar el mito y los artistas han contribuido con su particular visión a arnpliar y actualizar a esta deidad prehispánica.

\section{BIBLIOGRAFIA}

Crespo de la Serna, Jorge J., et al., Raúl Anguiano, EDAMEX, México, 1983. 40 siglos de arte mexicano, Herrero, 1960. Tomos 1 y 3.

Diego Rivera, Catálogo. Exposición en el Detroit Institute of Arts, Detroit, 1986.

Echeverría, Salvador. Orozco. Hospicio Cabañas, Enciclopedia de México, México, 1974.

Fermín Revueltas, colores, trazos y proyectos, Catálogo, Exposición Centro Cultural Universitario. UNAM, México, Noviembre, 1983. 
Fernández Barrera, Josefina, "La serpiente en la plástica mexicana", tesis de doctorado, UNAM, 1984.

Frescos de Orozco en Darmouth, SEP, México, 1944.

Gutiérrez Solana, Nelly, Las serpientes en el arte mexica, UNAM, México, 1987.

Historia del arte mexicano, SEP-INBA-SALVAT, México, 1972. Tomos 1-3, 10-12.

Homenaje a Juan O'Gorman 1905-1982, Catálogo, Exposición Palacio de Medicina UNAM, México, Junio-Agosto 1983.

Lafaye, Jacques, Quetzalcóatl y Guadalupe. La formación de la conciencia nacional en México, F.C.E., México, 1977.

León Portilla, Miguel, Quetzalcóatl, F.C.E., México, 1968.

López Austin, Alfredo, Hombre-dios. Religión y política en el mundo náhuatl, UNAM, México, 1973.

López Portillo, José Demetrio Sodi y Fernando Díaz Infante, Quetzalcóatl, SAHOP, México, 1977.

Orozco's frescoes in Guadalajara, Frances Toor Studios, México, 1960.

Pani, Mario y Enrique del Moral, La construcción de la Ciudad Universitaria del Pedregal, UNAM, México, 1979.

Pani, Mario, Los multifamiliares de Pensiones, Editorial Arquitectura, México, 1952.

Pascual Buxó, José, et al., En la pintura de Raúl Anguiano, Ediciones de Comunicación, México, 1986.

Piña Chan, Román, Quetzalcóatl, serpiente emplumada, F.C.E., México, 1977.

Rodríguez Prampolini, Ida, Juan O'Gorman arquitecto y pintor, UNAM, México, 1982.

Rufino Tamayo, 20 años de creación, Catálogo, Exposición INBA, México, 1987.

Santiago Silva, José de, Chávez Morado, vida, obra y circunstancias, 2 vols., Gobierno del Estado de Guanajuato, Guanajuato, 1984.

Séjourné, Laurette, El universo de Quetzalcóatl, F.C.E., México, 1962.

Suárez, Orlando $\mathrm{S}$, Inventario del muralismo mexicano, UNAM, México, 1972.

Tibol, Raquel, Arte Mexicano, época moderna contemporánea, Editorial Hermes, Mérico, 1964.

Tibol, Raquel, José Chávez Morado, UNAM, México, 1980. 